\title{
Review
}

\section{Thermal Input/Concentration Output Systems Processed by Chemical Reactions of Helicene Oligomers}

\author{
Sheng Zhang, Ming Bao and Masahiko Yamaguchi *
}

check for

updates

Citation: Zhang, S.; Bao, M.;

Yamaguchi, M. Thermal

Input/Concentration Output

Systems Processed by Chemical

Reactions of Helicene Oligomers.

Reactions 2022, 3, 89-117. https:/ /

doi.org/10.3390/reactions3010008

Academic Editors: Fleming

Martínez Rodriguez and Dmitry

Yu. Murzin

Received: 28 December 2021

Accepted: 18 January 2022

Published: 25 January 2022

Publisher's Note: MDPI stays neutral with regard to jurisdictional claims in published maps and institutional affiliations.

Copyright: () 2022 by the authors Licensee MDPI, Basel, Switzerland. This article is an open access article distributed under the terms and conditions of the Creative Commons Attribution (CC BY) license (https:// creativecommons.org/licenses/by/ $4.0 /)$.
State Key Laboratory of Fine Chemicals, Dalian University of Technology, Dalian 116024, China; shengzhang@dlut.edu.cn (S.Z.); mingbao@dlut.edu.cn (M.B.)

* Correspondence: yama@dlut.edu.cn

\begin{abstract}
This article describes thermal input/concentration output systems processed by chemical reactions. Various sophisticated thermal inputs can be converted into concentration outputs through the double-helix formation of helicene oligomers exhibiting thermal hysteresis. The inputs include high or low temperature, cooling or heating state, slow or fast cooling state, heating state, and cooling history. The chemical basis for the properties of the chemical reactions includes the reversibility out of chemical equilibrium, sigmoidal relationship and kinetics, bistability involving metastable states, positive feedback by self-catalytic chemical reactions, competitive chemical reactions, and fine tunability for parallel processing. The interfacing of concentration outputs in other systems is considered, and biological cells are considered to have been utilizing such input/output systems processed by chemical reactions.
\end{abstract}

Keywords: thermal input/concentration output systems; chemical reactions; thermal hysteresis; reversible; out of chemical equilibrium; bistability; self-catalysis; processing; interfacing

\section{Input/Output Systems}

The concept of information systems involving inputs and outputs is widely used in science, technology, and society [1]. Inputs are defined as signals or data received by a system, whereas outputs are defined as signals or data sent from it [2]. Inputs represent data and materials from external processes, and outputs are data and materials flowing out of transformation processes [3]. In other words, inputs for a system cause change, whereas the effects that occur on a system are outputs. Interfacing connects an input/output system to another [4-6] and facilitates the designing or adaptation of the outputs and inputs of two systems, enabling them to work together [7]. Overall, resources, such as materials, energy, information, and environment, are interfaced by a number of input/output systems leading to functions in the real world (Figure 1) [1]. For instance, an air conditioner controls room temperature, which involves the monitoring of environmental temperature, interfacing of electronic device input/output systems, and conducting heating and cooling functions.

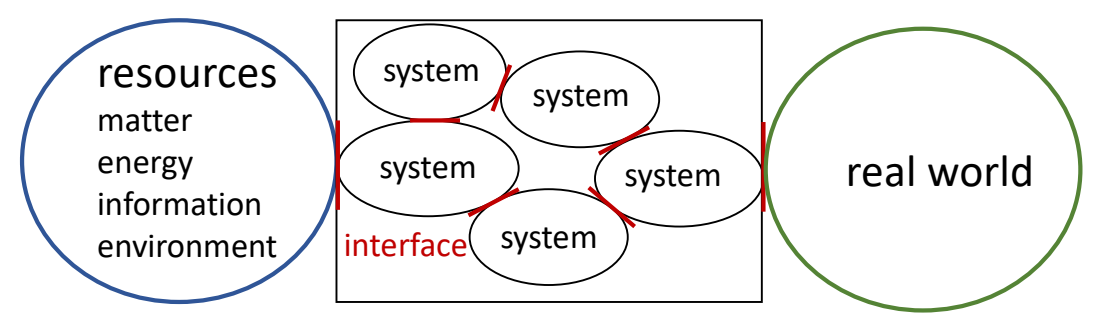

Figure 1. Input/output system with interfacing connects resources to the real world.

An electronic circuit converts an electric current or voltage input to provide an output of the same type, and an input/output system is interfaced with other systems and eventually leading to the real world [4-6]. Electronic circuits employ analog and digital signals, 
usually equipped with devices for the interconversion of analog and digital signals [8-11]. Analog signals are continuous quantities, whereas digital signals constitute a series of discrete quantities.

Computers employ a set of interfaced input/output systems that collect, retrieve, process, store, and distribute information to support decision making and control in an organization, employing digital signals of 0 s and $1 \mathrm{~s}$ as inputs or outputs [12,13].

The functions of biological cells can be considered as input/output systems, and various types of environmental information are transferred to cellular responses [14]. Homeostasis, growth, evolution, and genetics can be controlled through signal transduction, which transmits chemical or physical signals as a series of chemical reactions through a cell $[15,16]$. For instance, changes in external temperature are monitored on cell surfaces and processed in the input/output systems of cells, and responses against the temperature changes that occur. Biological cells employ input/output systems involving analog and digital signals and regulate the interconversion of signals [17-20]. The structures of biological networks parallel those of information networks in electronic circuits in terms of complexity [21].

Between input and output is processing, which is defined as how input is related to output in a system and involves enhancement, attenuation, bifurcation, amplification, evaluation, and positive or negative feedback [22]. Processing by electronic circuits is conducted by resistors, transducers, inducers, and diodes [7]. Processing by computers includes the conversion of raw data into machine-readable forms, flow of data through the central processing unit (CPU) and memory to output devices, and formatting or transformation of outputs [12,13]. Processing in the nervous systems of animals is an example of processing through chemical reactions, involving the sequential opening of ion channels on neurons with one direction of an electric current and release of chemical neurotransmitters at synapsis for the modulation of the current $[14,23]$.

Input/output systems are connected through interfacing, which is defined here as the conversion of an output of a system into an input in another system [4-6]. Efficiency in interfacing affects the efficiency of relating resources and functions leading to the real world. For instance, when an output obtained through processing by a chemical reaction is a concentration of a compound, the concentration is the input in other input/output systems and processed by other chemical reactions. Thus, the way an output from one system can be accepted in other systems is important.

The concept of input/output systems processed by chemical reactions is essential to biology. However, biological events are extremely complex and are difficult to analyze and understand. Although input/output system models have been studied through mathematical methods in systems biology [24-28], experimental studies are few because of inadequate chemical reactions suitable for processing.

Synthetic thermal input/concentration output systems processed by chemical reactions are described in this study. We developed synthetic organic compounds that experimentally exhibit thermal hysteresis through chemical reactions [29-31]. Studies on thermal hysteresis have suggested their use in thermal input/concentration output systems processed by chemical reactions. Chemical reactions can be used in processing sophisticated thermal inputs and their conversion into concentration outputs. Such chemical reactions exhibit thermal properties that are considerably different from those of ordinary chemical equilibria and chemical reactions and appear to exhibit behavior similar to those of thermal responses of biological cells. The present study presents the following questions: what can be done by thermal input/concentration output systems processed by chemical reactions? What properties are involved in such chemical reactions? What is the chemical basis for the properties? 


\section{Thermal Input/Concentration Output Systems Processed by Chemical Reactions}

\subsection{Processing by Chemical Reactions}

Proper responses to temperature changes are critical to living things. Biological responses (real world) to temperature changes (resource) involves a number of input/output systems processed by chemical reactions, and these systems are connected to each other through interfacing (Figure 2). Monitoring a small increase in environmental temperature of several centigrade makes flowers in spring, while in the human body it triggers cooling for homeostasis. Biological cells manipulate these phenomena through chemical reactions under ambient conditions. Thermal input/concentration output systems processed by chemical reactions, which convert signals of temperature changes to concentration outputs, respond to various temperature changes. The mechanisms of the biological thermal monitoring and responses are not fully clear yet, so studying synthetic input/output systems using synthetic compounds is interesting.

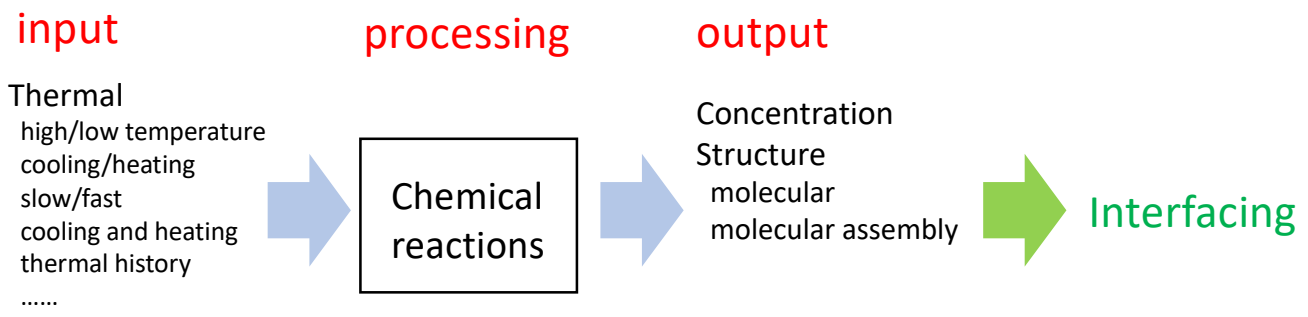

Figure 2. Thermal input/concentration output systems processed by chemical reactions and their interfacing.

In principle, any chemical reaction can be used in processing in thermal input/concentration output systems because chemical reactions are affected by temperature. However, the properties of chemical reactions employed in biological cells are considerably different from those of ordinary chemical equilibria and chemical reactions under ambient conditions. For instance, ordinary chemical reactions are generally not sensitive enough to small temperature changes under ambient conditions. This feature will be discussed in Section 2.2. The subjects of interest then are the properties of chemical reactions, which can be involved in thermal input/concentration output systems. The chemical basis for these properties will be discussed in Section 3. It is also discussed how an analog signal of a thermal input can be converted into a digital signal of a concentration output through chemical reaction [23].

A chemical reaction transforms one set of chemical substances into another by rearranging covalent and noncovalent chemical bonds [32-35]. The mechanisms of a chemical reaction are complex and include (1) a large number of transition and intermediate states; (2) a large number of pathways connecting these states; (3) pathways affected by environmental conditions, including temperature; (4) flux of a huge number of molecules visiting the pathways; (5) fluxes exhibiting complex properties with dynamic nature; and (6) fluxes that are sensitively affected by environmental conditions, which include temperature, pressure, medium, and concentration. Accordingly, thermal input/concentration output systems processed by chemical reactions can manipulate sophisticated thermal inputs.

Molecules and molecular assemblies are discriminated in this article. The structure and chemical reaction of a molecule are described using quantum mechanics and depicted by the arrangements of atoms and bonds between atoms. Quantum mechanics describe an elementary chemical reaction of a single molecule with regard to how its molecular structure changes. Such change is generally completed in picoseconds. A molecular assembly is an ensemble of a large number of molecules, usually quantified using Avogadro's number, and its behavior is described with statistical mechanics. The structures of molecular assemblies involve interactions between molecules and their structures and are diverse depending on the states of solutions (gas, liquid, crystal, gel, and liquid crystal states). Chemical reactions in molecular assemblies are significantly affected by the nature of interactions between molecules and environmental conditions. Many molecules do not simultaneously react, 
reacting instead one by one, and the reactions generally require reaction times ranging from seconds to hours or days. This article focuses on how molecular assemblies behave in processing and interfacing in thermal input/concentration output systems and discusses different concepts from the perspective of a single molecule.

Thermal input/concentration output systems processed by the chemical reactions of molecular assemblies can manipulate diverse thermal phenomena (Figure 2): Diverse temperature changes can be inputs, including high or low temperature, cooling or heating states, slow or fast cooling and heating states, and cooling history; diverse outputs can be provided, which include the structures and concentrations of product molecules and molecular assemblies along with their thermal, mechanical, and optical, properties.

In Section 2.2, the temperature dependency of ordinary chemical equilibria and bimolecular chemical reactions is summarized. In Section 3, the chemical basis for the properties of chemical reactions for the processing of thermal inputs are considered. In Section 4, the scope of this article is noted. In Sections 5 and 6, experimental thermal input/concentration output systems are described, which are based on our experimental studies of thermal hysteresis using helicene oligomers. In Section 7, the interfacing of input/output systems is discussed. In Section 8, the conclusion is provided.

\subsection{Temperature Dependency of Chemical Reactions}

\subsubsection{Chemical Equilibrium}

Discussions are started in this section by exploring the temperature effect of an ordinary chemical equilibrium $2 \mathbf{A} \leftrightarrows \mathbf{B}$ and an ordinary bimolecular reaction $2 \mathbf{A} \rightarrow \mathbf{B}$ [35]. Their properties appear to be considerably different from those involved in biological cells under ambient conditions.

In a chemical equilibrium $2 \mathbf{A} \leftrightarrows \mathbf{B}$ with the equilibrium constant $K=[\mathbf{B}] /[\mathbf{A}]^{2}=$ $[\mathbf{B}] /\left([\mathbf{A}]_{0}-2[\mathbf{B}]\right)^{2}$ and $[\mathbf{A}]_{0}=[\mathbf{A}]+2[\mathbf{B}]$, temperature is related by $K=\exp (-\Delta G / R T)$, in which $\Delta G, R$, and $T$ are the Gibbs free energy difference, gas constant, and absolute temperature, respectively. When temperature is changed stepwise, [B] also changes stepwise (Figure 3a). An extremely large reaction rate is involved in concentration changes to stepwise temperature changes. No delay phenomenon occurs.

(a)

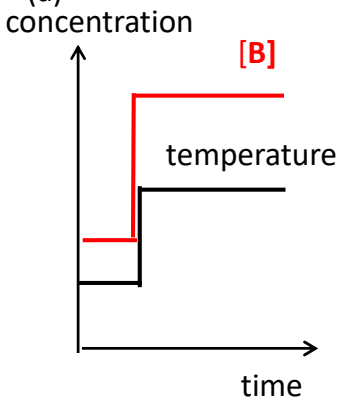

(b)

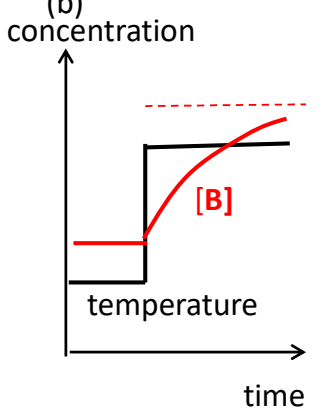

(c)

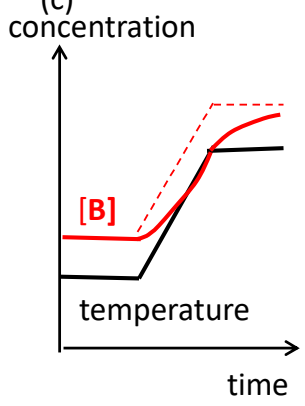

Figure 3. Thermal input and concentration output (a) under chemical equilibrium by a stepwise temperature change, (b) with delay-to-approach chemical equilibrium by a stepwise temperature change, and (c) with delay-to-approach chemical equilibrium by a gradual temperature change. Black lines show temperature changes; red lines show concentration changes; red dashed lines show concentration at chemical equilibrium.

However, the sensitivity of concentration changes against stepwise temperature changes at ambient temperature is not extremely large under ordinary chemical equilibrium with a fixed $\Delta G$. For simplicity, in a chemical equilibrium $\mathbf{A} \leftrightarrows \mathbf{B}, K=[\mathbf{B}] /[\mathbf{A}]$ and $[\mathbf{A}]_{0}=[\mathbf{A}]+[\mathbf{B}],[\mathbf{B}]=K[\mathbf{A}]_{0} /(K+1)=[\mathbf{A}]_{0} /(1+1 /(\exp (-\Delta G / R T)))$ is provided. For instance, when $\Delta G=-4.15 \mathrm{KJ} \mathrm{mol}^{-1}$ and $R=8.3 \mathrm{~J} \mathrm{~mol}^{-1} \mathrm{~K}^{-1}$, [B] $=0.53[\mathrm{~A}]_{0}$ at $T=300 \mathrm{~K}$ and $[\mathbf{B}]=0.50[\mathbf{A}]_{0}$ at $T=310 \mathrm{~K}$. This shows a decrease in $[\mathbf{B}]$ of less than $10 \%$ after a temperature increase of $10^{\circ} \mathrm{C}$. Thus, chemical reactions with large temperature dependency 
at ambient conditions may be involved in thermal input/concentration output systems in biological cells, which are beyond chemical equilibrium.

\subsubsection{Irreversible Chemical Reactions out of Chemical Equilibrium}

When delay occurs in a chemical reaction in response to a stepwise temperature change, the system moves away from chemical equilibrium, and transient delay phenomena occur when the reactions approach chemical equilibrium (Figure 3b). Note that delay phenomena occur out of chemical equilibrium, which is in contrast to chemical equilibrium without delay (Figure $3 \mathbf{b}$, compare red dashed line). The reaction rate $-d[\mathbf{A}] / d t=k[\mathbf{A}]^{2}$ of the irreversible bimolecular chemical reaction $2 \mathbf{A} \rightarrow \mathbf{B}$ is described according to the chemical kinetics based on transition state theory [34,35]. The rate constant is expressed by $k=A \exp \left(-E_{\mathrm{a}} / R T\right)$, in which $A, E_{\mathrm{a}}, R$, and $T$ are frequency factor, activation energy, gas constant, and absolute temperature, respectively. The reaction rate under constant temperature (isothermal) conditions against a stepwise temperature change is described by the change of $k$ according to the equation. A $10^{\circ} \mathrm{C}$ increase in temperature is considered to increase the initial reaction rate two- to three-fold under ambient conditions. This phenomenon implies that temperature change induces a small change in the concentration of $\mathbf{B}$ at the initial stage of the chemical reaction, at which the conversion or the concentration of $\mathbf{B}$ is extremely low. Small increases in concentrations under ambient conditions may be difficult to interface, and thermal input/concentration output systems with high sensitivity to temperature changes are used in biological cells.

Gradual temperature changes can be provided for thermal inputs to the thermal input/concentration output systems processed by the ordinary bimolecular chemical reaction $2 \mathbf{A} \rightarrow \mathbf{B}$ (Figure 3c). When delay occurs, the kinetics of the chemical reactions are more complex than the isothermal kinetics of chemical reactions initiated by stepwise temperature changes [36,37]. The above chemical kinetic model expressed by the rate constant $k$ is considered simple in its depiction of such non-isothermal chemical reactions. The reason is that reaction mechanisms are often changed by temperature changes and apparent $A$ and $E_{\mathrm{a}}$ changes [38-40]. It may be reasonable to consider that reaction rates under gradual temperature increases are lower than the rates under stepwise temperature increases. Then, the ordinary irreversible bimolecular chemical reaction $2 \mathbf{A} \rightarrow \mathbf{B}$ may not be sensitive enough during stepwise and gradual temperature changes in biological cells.

The properties of chemical reactions suitable for thermal input/concentration output systems are proposed in Section 3: (1) reversible chemical reactions out of chemical equilibrium, (2) sigmoidal relationship and kinetics for bistability involving metastable states, (3) positive feedback by self-catalytic chemical reactions, (4) competitive chemical reactions that exhibit diverse outputs, and (5) fine-tunability for parallel processing to broaden applicable temperature ranges. In addition, large differences in the structures of substrates and products are beneficial for interfacing among input/output systems. Such chemical reactions are not common, and their development is useful in elucidating biological thermal events.

\section{Properties of Chemical Reactions for Thermal Input/Concentration Output Systems}

\subsection{Reversible Chemical Reactions out of Chemical Equilibrium}

Reversibility in chemical reactions can provide advantageous properties to thermal input/concentration output systems processed by chemical reactions. The initial state or substrates can be regenerated from the final state or products, and the thermal input/concentration output system can be prepared to the next input. In addition, various notable concentration phenomena appear when processed by reversible chemical reactions with different pathways during cooling and heating. This section describes such reversible chemical reactions out of chemical equilibrium. Their bistable nature will be described in Section 3.2.

A typical example of reversible chemical reaction is chemical equilibrium $2 \mathbf{A} \leftrightarrows \mathbf{B}$, in which the forward and backward reactions are balanced (Figure 4a) [35]. Their behaviors 
are described by the thermodynamics. As noted in Section 2.2, chemical equilibrium exerts small concentration changes under ambient conditions by small temperature changes.

(a)

$2 A$ B (b)

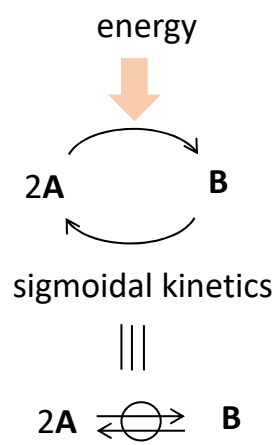

(c)

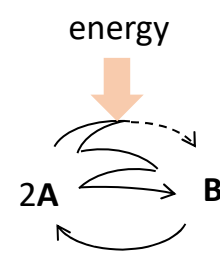

Figure 4. (a) Reversible chemical reaction $2 \mathbf{A} \leftrightarrows \mathbf{B}$ under chemical equilibrium. (b) Reversible chemical reaction $2 \mathbf{A}$ B by different pathways, in which external energy is supplied to regenerate $2 \mathbf{A}$ from B. (c) Conditions are changed before the completion of reversible chemical reaction $2 \mathbf{A}$, which inverts the direction.

Reversible chemical reactions out of chemical equilibrium are described as follows. Bimolecular chemical reaction $2 \mathbf{A} \rightarrow \mathbf{B}$ occurs energetically in a downhill manner and proceeds in the forward direction (Figure $4 \mathrm{~b}$ ). The forward reaction can be reversed to provide chemical reaction $\mathbf{B} \rightarrow 2 \mathbf{A}$, when appropriate chemical reagents or external energies are supplied to $\mathbf{B}$ to regenerate $2 \mathbf{A}$. Then, the forward and backward reactions occur by different pathways. When the addition and removal of materials and energy such as the chemical reagents are involved, the reversible chemical reactions $2 \mathbf{A} \rightarrow \mathbf{B}$ and $\mathbf{B} \rightarrow 2 \mathbf{A}$ occur in an open system. Such reversible chemical reactions proceed out of chemical equilibrium and are noted here by $2 \mathbf{A} \mathbf{B}$ and distinguished from chemical equilibrium $2 \mathbf{A} \leftrightarrows \mathbf{B}[29-31]$.

A reversible chemical reaction $2 \mathrm{~A}$ B with different pathways during cooling and heating can occur in a closed system, which involves the addition and removal of thermal energy but not materials. Such reversible chemical reaction 2A B might not be easy to consider. However, it can occur when the relative thermodynamic stability of $2 \mathbf{A}$ and $\mathbf{B}$ is inverted by cooling and heating and delay of the chemical reaction against the occurring temperature changes.

An example of the reversible chemical reaction $2 \mathbf{A} \mathbf{B}$ in a closed system is described as follows. At a high temperature, $2 \mathbf{A}$ is thermodynamically stable, and dissociation reaction $\mathbf{B} \rightarrow 2 \mathbf{A}$ occurs, the process of which is out of chemical equilibrium when delay against the temperature changes is involved [32-34]. At a low temperature, the relative thermodynamic stability inverts, and $\mathbf{B}$ becomes thermodynamically stable. Then, association reaction $2 \mathbf{A} \rightarrow \mathbf{B}$ occurs with delay, which proceeds towards chemical equilibrium. The reversible chemical reaction $2 \mathbf{A} \mathbf{B}$ occurs in a different pathway in the formation of $2 \mathbf{A}$ and $\mathbf{B}$ by heating and cooling, respectively. Accordingly, two states appear at the same temperature, range which is bistability.

When stepwise temperature change is provided, the pathway with delay can be described by chemical kinetics under isothermal conditions, which are expressed by concentration/time profiles (Figure 3b) [32-34]. When temperature is gradually changed, the different pathways with delay are expressed by thermal hysteresis in concentration/temperature profiles. Such reversible chemical reactions are in contrast to chemical equilibrium, in which no delay occurs during cooling and heating (Figure 3a).

Another advantage of the reversible chemical reaction is that temperature can be changed before its completion reaching chemical equilibrium, and the direction of the chemical reactions can be inverted during the chemical reaction (Figure 4c). Then, concen- 
tration outputs against thermal inputs exhibit various complex phenomena, which will be described in Sections 5 and 6.

\subsection{Bistability by Thermal Hysteresis Involving Sigmoidal Relationship and Kinetics}

Bistability is defined in this article as a phenomenon with two rested states of a thermal input/concentration output system at the same temperature range, which are interconvertible [23,41,42]. Bistability is an essential feature of chemical reactions for processing in the systems, and this section discusses bistability which occurs through the reversible chemical reaction $2 \mathbf{A} \mathbf{B}$ out of chemical equilibrium in a closed system. Here, the bistability is associated with thermal hysteresis involving sigmoidal relationship and kinetics. Such systems can convert various sophisticated thermal inputs into two different states of concentration outputs.

For the discussion of bistability, limit states are defined as states where no changes in concentrations occur through temperature changes (Figure 5). Two limit states are ideally described by the Heaviside relationships between thermal input and concentration output, which involves a stepwise change in concentration by temperature (Figure 5a) [43]. Then, an extremely small temperature change exerts a large difference in concentration. In addition, two flat domains provide tolerance, which stabilizes the limit states to temperature perturbations. However, the Heaviside step relationship is difficult to realize experimentally through chemical reactions.

(a)

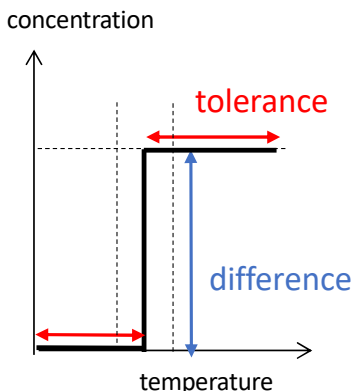

(b)

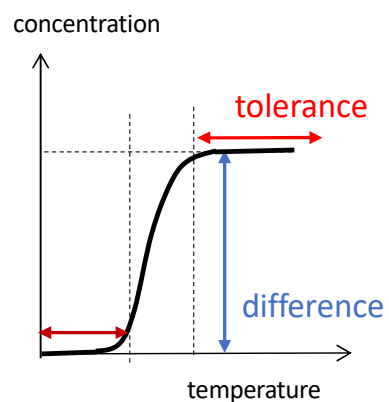

(c)

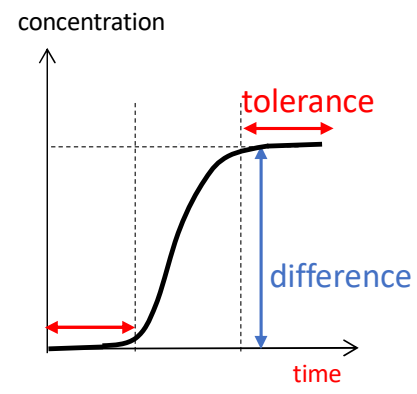

Figure 5. Limit states of (a) the Heaviside step relationship and (b) sigmoidal relationship out of chemical equilibrium shown by concentration/temperature profiles. (c) Sigmoidal kinetics shown by concentration/time profiles. Dotted lines indicate differences in concentration against a temperature change.

Sigmoidal relationship exhibits S-shaped curves and can be an experimental analog to the Heaviside relationship (Figure 5b). The concentration in a sigmoidal relationship in a temperature/concentration profile can be characterized, for example, by temperature $T$ with $T^{a} /\left(1+T^{a}\right)$ involving a positive constant $a$ or the Hill coefficient in biology [44,45]. Sigmoidal relationship provides two limit states with flat domains at different temperatures, and these states provide tolerance to small temperature perturbations. Such stability is especially important when limit states are metastable or out of equilibrium. Otherwise, temperature perturbations readily exert effects that changes the metastable limit states toward chemical equilibrium.

Bistability in thermal hysteresis can be described based on the nature of sigmoidal relationship with two limit states. Thermal hysteresis is a phenomenon involving different pathways during cooling and heating and is expressed by different cooling and heating curves in concentration/temperature profiles [29-31]. The phenomenon can ideally be shown by two cooling and heating curves with the two Heaviside relationships between two limit states, which provide bistability (Figure 6a, red bold lines). Experimental thermal hysteresis treated in this article is exerted by a reversible bimolecular chemical reaction 2A $\mathbf{B}$ out of chemical equilibrium, which is expressed by two sigmoidal relationships 
during cooling and heating (Figure 6b). Note that two limit states at the same temperature range provide bistability (Figure $6 \mathrm{~b}$, red bold lines). Two sigmoidal curves exhibit bistability at the same temperature range during cooling and heating, which involves large differences in concentration and tolerances with stability against temperature perturbations. The temperature range of the bistability is a critical factor to be considered: A broad range exerts bistability in a broad temperature range, and a narrow range exerts bistability at a specific temperature. For the interfacing of the concentration output to other systems, large differences in concentrations are beneficial. Note that thermal hysteresis occurs by the delay of chemical reaction against temperature change and is a phenomenon out of chemical equilibrium (Figure 6b, compare dashed line).

(a)

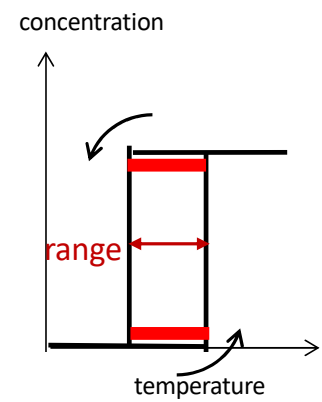

(b)

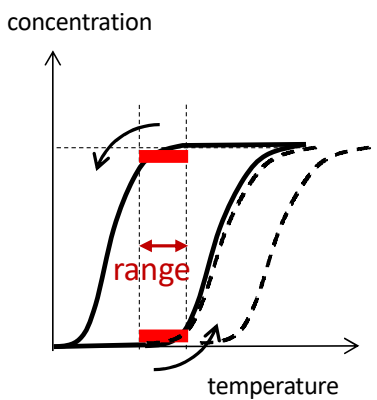

(c)

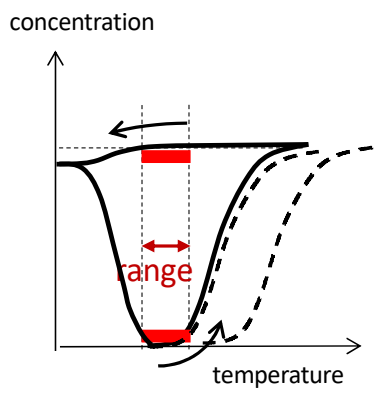

Figure 6. Bistability by thermal hysteresis involving (a) the Heaviside step relationship, (b) and (c) sigmoidal relationships shown by temperature/concentration profiles. Bold red lines indicate the temperature ranges of bistability with tolerance. Dashed lines indicate the examples of chemical equilibrium. Black arrows indicate cooling and heating.

Various types of thermal hysteresis can appear, which are also explained by sigmoidal relationships and bistability [29-31]. For example, consider a thermal hysteresis with a small decrease in concentration during cooling and significant decrease and increase during heating (Figure 6c), which will be noted in Section 5.2. The phenomena can be interpreted by the involvement of three sigmoidal relationships, one during cooling and two during heating, and bistability occurs at the same temperature range (Figure $6 \mathrm{c}$, red bold lines). This is in contrast to the above-mentioned thermal hysteresis (Figure 6b), in which two sigmoidal relationships are involved during cooling and heating. The two/three sigmoidal relationships provide phenomena out of chemical equilibrium (Figure $6 c$, compare dashed lines).

Sigmoidal kinetics is defined here as S-shaped or slow-fast-slow reaction kinetics depicted by concentration/time profiles under isothermal condition (Figure 5c) [46,47], which is a time-dependent phenomenon that is different from the temperature-dependent phenomenon of sigmoidal relationships (Figure 5b). Sigmoidal kinetics is different from the hyperbola or exponential kinetics of ordinary chemical reactions with fast-slow reaction kinetics. A slow chemical reaction is followed by a rapid chemical reaction involving acceleration, and then the chemical reaction is retarded by approaching chemical equilibrium. Bistability appears in the sigmoidal kinetics at the initial and later states at the same temperature. The bistability can involve metastable states, which are conducive to interfacing when their lifetimes are long enough. Sigmoidal kinetics are not common in chemistry compared with hyperbola/exponential kinetics in ordinary chemical reactions, but they often appear in biology. Thus, development and understanding of such chemical reactions are interesting.

Thermal hysteresis involving delay can provide bistability with metastable states out of chemical equilibrium (Figure $6 \mathrm{~b}, \mathrm{c}$ ). Large differences in concentrations can be provided, which exhibit sensitive nature in outputs against small changes of thermal inputs. When the metastable states have sufficiently long lifetimes, they can be beneficial for interfacing. Thus, thermal input/concentration output systems processed by chemical reactions can be used 
in the conversion of an analog signal of thermal input to a digital signal of concentration, which employ bistability [23].

\subsection{Positive Feedback by Self-Catalytic Chemical Reaction}

Positive feedback is an essential mechanism used in the functions of biological cells and accelerates chemical reactions with progress [14]. Positive feedback can amplify the properties of thermal input/concentration output systems processed by chemical reactions. Such properties have been studied mathematically through systems biology [47-51]. It is thus interesting experimentally to study such properties, which can promote understanding of biological phenomena and development of novel material functions.

An example of positive feedback is self-catalytic chemical reaction $2 \mathbf{A}+\mathbf{B} \rightarrow 2 \mathbf{B}$, in which product $\mathbf{B}$ catalyzes the reaction of $2 \mathbf{A}$ to become $\mathbf{B}$ (Figure 7a) [29-31]. The reaction of $\mathbf{A}$ and $\mathbf{B}$ forms a complex $\mathbf{A}-\mathbf{B}$, which reacts with another $\mathbf{A}$ to form $2 \mathbf{B}$, which is a phenomenon of the molecular level. Self-catalytic chemical reactions exhibit characteristic phenomena of concentration changes at the molecular assembly level (Figure $7 \mathrm{~b}$ ). The initial chemical reaction $2 \mathbf{A} \rightarrow \mathbf{B}$ is slow, which is accelerated by self-catalytic chemical reaction $2 \mathbf{A}+\mathbf{B} \rightarrow 2 \mathbf{B}$ because of the increase in the product and catalyst $\mathbf{B}$. Then, $\mathbf{B}$ is formed from $2 \mathbf{A}$ nearby in spatially heterogeneous manner. The formation of $\mathbf{B}$ retards as chemical equilibrium with homogeneous state is approached. As a consequence, sigmoidal kinetics occurs. It is in contrast to ordinary bimolecular chemical reactions, in which the maximum initial rate is achieved and rate decreases with progress.

(a)

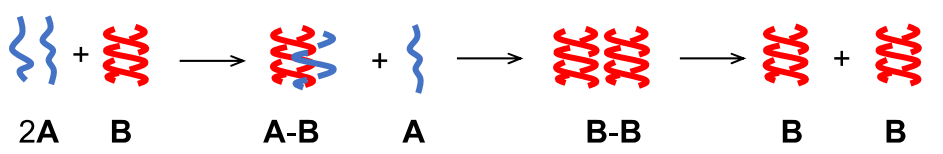

(b)

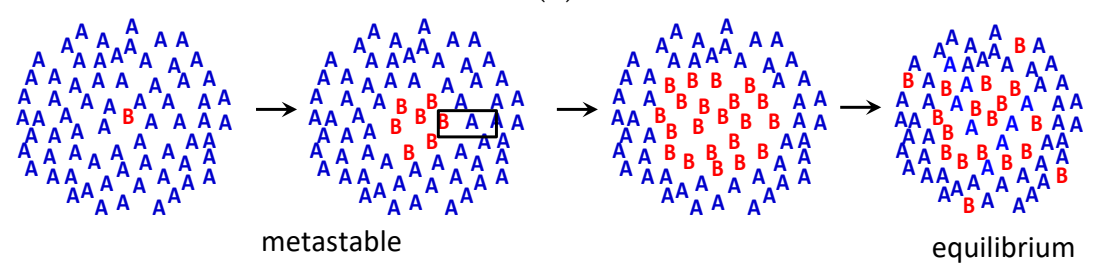

Figure 7. Schematic presentations of self-catalytic reaction $2 \mathbf{A}+\mathbf{B} \rightarrow 2 \mathbf{B}(\mathbf{a})$ at the molecular level and (b) at the molecular assembly level. Reproduced from ref. [52,53] with permission from Wiley.

Seeding effect appears, in which the addition of $\mathbf{B}$ to $2 \mathbf{A}$ significantly accelerates the chemical reaction. Spatially heterogeneous nature can appear because self-catalytic chemical reactions occur with molecules close each other (Figure 7b).

When self-catalytic chemical reactions are involved in thermal input/concentration output systems, a small change in temperature can induce a large increase in concentration. Thus, sigmoidal relationship and kinetics appear in concentration/temperature profiles and concentration/time profiles, respectively, which can provide properties beneficial for interfacing. The properties of self-catalytic chemical reactions are described in recent review articles [29-31].

\subsection{Competitive Chemical Reactions}

Thermal input/concentration output systems processed by competitive chemical reactions $2 \mathbf{A} \rightarrow \mathbf{B}$ and $2 \mathbf{A} \rightarrow \mathbf{C}$ can manipulate sophisticated thermal inputs and exhibit a more complex nature than those processed by a single chemical reaction $2 \mathbf{A} \rightarrow \mathbf{B}$ (Figure 8). The systems can provide the bistability of $\mathbf{B} / \mathbf{C}, \mathbf{A} / \mathbf{B}$, and $\mathbf{A} / \mathbf{C}$ with three structures $\mathbf{A}, \mathbf{B}$, and $\mathbf{C}$, among which $\mathbf{B} / \mathbf{C}$ is the bistability between two products $\mathbf{B}$ and $\mathbf{C}$ (Figure $8 \mathrm{a}$ ). The systems involve reverse chemical reactions, such as $\mathbf{B} \rightarrow 2 \mathbf{A}, \mathbf{C} \rightarrow 2 \mathbf{A}$, and $\mathbf{B} \rightarrow \mathbf{C} \rightarrow 2 \mathbf{A}$ (Figure $8 \mathbf{b}$ ). 
The systems involve two competitive self-catalytic chemical reactions $2 \mathbf{A}+\mathbf{B} \rightarrow 2 \mathbf{B}$ and $2 \mathbf{A}+\mathbf{C} \rightarrow 2 \mathbf{C}$. The systems can involve two and more metastable states, such as $2 \mathbf{A}$ and $\mathbf{B}$ (Figure 8b) [29-31].

a)

products
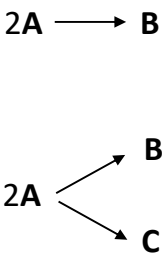

b)

reversible
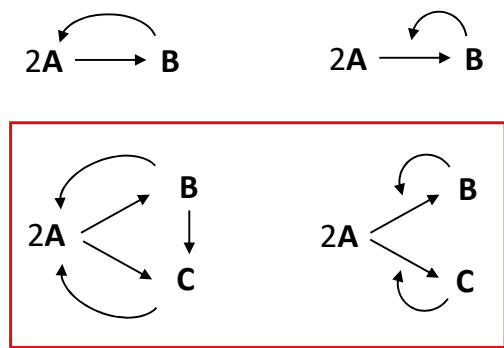

Figure 8. (a) Ordinary competitive chemical reactions $2 \mathbf{A} \rightarrow \mathbf{B}$ and $2 \mathbf{A} \rightarrow \mathbf{C}$, and (b) reversible competitive chemical reactions $\mathbf{B} 2 \mathbf{A} \mathbf{C}$ involving self-catalytic chemical reactions $2 \mathbf{A}+\mathbf{B} \rightarrow 2 \mathbf{B}$ and $2 \mathbf{A}+\mathbf{C} \rightarrow 2 \mathbf{C}$ (red square), which are compared with chemical reaction $2 \mathbf{A} \rightarrow \mathbf{B}$.

In ordinary competitive chemical reactions $2 \mathbf{A} \rightarrow \mathbf{B}$ and $2 \mathbf{A} \rightarrow \mathbf{C}$, products $\mathbf{B}$ and $\mathbf{C}$ can be switched by applying different chemical reagents, and the reverse chemical reactions $\mathbf{B} \rightarrow 2 \mathbf{A}$ and $\mathbf{C} \rightarrow 2 \mathbf{A}$ can occur by applying other chemical reagents. The bistability by $\mathbf{B} / \mathbf{C}$ occurs in an open system, in which materials and energy are exchanged with those outside of the system. In general, a large external energy is required as provided by chemical reagents, and byproducts derived from the reagents need to be removed.

Temperature changes in closed systems generally do not switch $\mathbf{B}$ and $\mathbf{C}$ in the ordinary bimolecular competitive chemical reactions $2 \mathbf{A} \rightarrow \mathbf{B}$ and $2 \mathbf{A} \rightarrow \mathbf{C}$ [32-35]. The chemical kinetics describe rate constants for the formation of $\mathbf{B}$ and $\mathbf{C}$ by $k_{\mathrm{B}}=A_{\mathrm{B}} \exp \left(-E_{\mathrm{aB}} / R T\right)$ and $k_{\mathrm{C}}=A_{\mathrm{C}} \exp \left(-E_{\mathrm{aC}} / R T\right)$, respectively, which are governed by $A$ and $E_{\mathrm{a}}$. When the mechanisms of two chemical reactions are similar when $A_{\mathrm{B}}=A_{\mathrm{C}}$, the ratio $k_{\mathrm{B}} / k_{\mathrm{C}}=$ $\exp \left(-\left(E_{\mathrm{aB}}-E_{\mathrm{aC}}\right) / R T\right)$ is a function of $T$ and the difference in the activation energy $E_{\mathrm{aB}}-E_{\mathrm{aC}}$. Given that $E_{\mathrm{aB}}-E_{\mathrm{aC}}$ is fixed by the involvement of similar mechanisms, the ratio $k_{\mathrm{B}} / k_{\mathrm{C}}$ monotonously changes as temperature changes, and the concentrations of $\mathbf{B}$ and $\mathbf{C}$ are not inverted by temperature changes.

When competitive self-catalytic reactions $2 \mathbf{A}+\mathbf{B} \rightarrow 2 \mathbf{B}$ and $2 \mathbf{A}+\mathbf{C} \rightarrow 2 \mathbf{C}$ are involved, bistability with switching between two products $\mathbf{B}$ and $\mathbf{C}$ can occur, which is exerted by thermal inputs in closed systems. Then, either $\mathbf{B}$ or $\mathbf{C}$ can predominate because the formation of $\mathbf{B}$ and $\mathbf{C}$ is governed by the efficiency of the self-catalytic chemical reactions and the reactions are highly dependent on temperature [52,53].

The reversible competitive chemical reactions, expressed by $\mathbf{B} 2 \mathrm{~A}$ C, exhibit complex phenomena, especially when temperature changes are provided during the chemical reaction before reaching chemical equilibrium (Figure $4 \mathrm{c}$ ). Depending on thermal inputs, complex increases and decreases in $2 \mathbf{A}, \mathbf{B}$, and $\mathbf{C}$ occur, which involve two or more metastable states. Note that metastable states can be beneficial for interfacing when the states have sufficiently long lifetime.

Sequential chemical reactions $2 \mathbf{A} \rightarrow \mathbf{B} \rightarrow \mathbf{C}$ can exhibit the bistability of $\mathbf{A} / \mathbf{B}, \mathbf{A} / \mathbf{C}$, and $\mathbf{B} / \mathbf{C}$. When $\mathbf{C}$ is under chemical equilibrium and $\mathbf{B}$ is metastable, $\mathbf{B}$ is initially formed from $2 \mathrm{~A}$ and eventually $\mathbf{C}$ under an isothermal condition. When $2 \mathrm{~A}$ can be regenerated by thermal treatment, the reversible chemical reactions $2 \mathrm{~A} \Leftarrow \mathbf{B}=\mathbf{C}$ occur in a closed system. When self-catalytic reactions $2 \mathbf{A}+\mathbf{B} \rightarrow 2 \mathbf{B}$ and $\mathbf{B}+\mathbf{C} \rightarrow 2 \mathbf{C}$ are involved, complex phenomena due to competitive acceleration occur.

Thermal input/concentration output systems processed by competitive chemical reactions convert sophisticated thermal inputs to concentration outputs. Notably, bistability involving metastable states can exhibit memory effect and future prediction. For example, 
sequential chemical reactions $2 \mathbf{A} \rightarrow \mathbf{B} \rightarrow \mathbf{C}$ under isothermal condition involve a metastable B. The formation of $\mathbf{B}$ contains information that $\mathbf{B}$ forms from $2 \mathbf{A}$ because limited pathways and conditions are available to form $\mathbf{B}$ through a memory effect. The formation of $\mathbf{B}$ indicates that $\mathbf{C}$ under chemical equilibrium will form in future [54].

\subsection{Fine-Tuning for Parallel Processing}

Thermal input/concentration output systems processed by chemical reactions can respond to various sophisticated thermal inputs and provide the outputs involving bistability. However, the applicable temperature range of each system is limited because a chemical reaction generally occurs under limited conditions. Thus, different systems are required to cover broad temperature ranges by processing with chemical reactions (Figure 9). Such limited temperature ranges are in contrast to the ranges of a digital thermometer, which has a broad temperature range (for example, between 0 and $100^{\circ} \mathrm{C}$ ), using a single apparatus. However, thermometers do not monitor sophisticated thermal inputs, and outputs are limited to digital numbers.

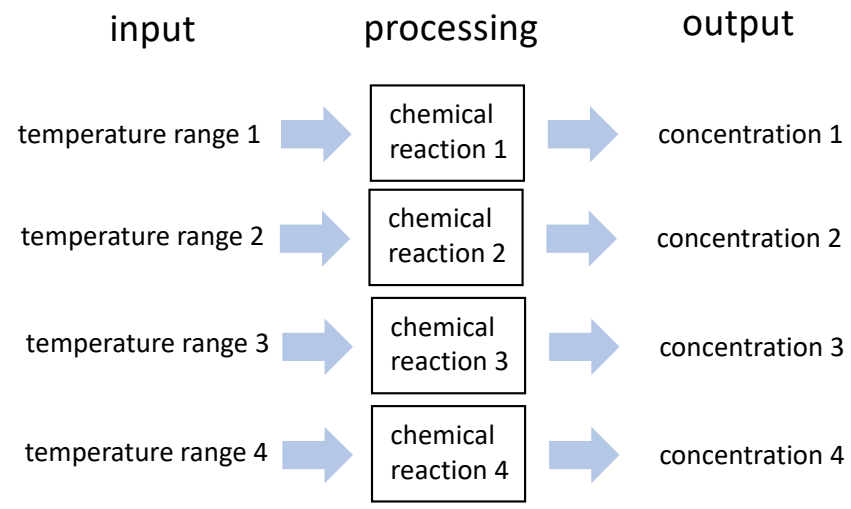

Figure 9. Parallel processing to cover broad temperature ranges employing different thermal input/concentration output systems processed by chemical reactions.

Biological cells monitor temperature by proteins using chemical reactions. They are highly sensitive but seem to be limited to specific small temperature ranges $[55,56]$. A cell does not need to know numerical temperatures between $0{ }^{\circ} \mathrm{C}$ and $100{ }^{\circ} \mathrm{C}$, but they need to know the difference between the present temperature and the optimum temperature, to which the cell quickly responds. An example of temperature monitoring system employs a class of TRP proteins: TRPA1 responds below $17^{\circ} \mathrm{C}$, TRPV1 above $42{ }^{\circ} \mathrm{C}$, and TRPM8 between $8{ }^{\circ} \mathrm{C}$ and $25^{\circ} \mathrm{C}[57,58]$. Thus, different proteins applicable to small temperature ranges are employed. These monitoring systems likely involve clusters of proteins and any change to the structure of a single protein or a small number of proteins is amplified to many nearby proteins. Therefore, the input of a subtle temperature change is sensitively processed to provide concentration outputs, which are beneficial for interfacing with other systems, and cells respond to temperature changes in the real world.

The involvement of different thermal input/concentration output systems to cover a range of temperature is termed here as parallel processing. Such different systems processed by chemical reactions can be obtained by the small modifications of the systems regarding the molecular and molecular assembly structures along with reaction conditions, such as concentrations, media, and chemicals. Chemical reactions employed in the synthetic thermal input/concentration output systems can readily be fine-tuned for parallel processing. 


\section{Scope of This Article}

Chemical basis for the properties of chemical reactions employed for processing in thermal input/concentration output systems, has been discussed in Section 3. Reversible chemical reactions out of chemical equilibrium can exhibit various thermal properties and contain rich information, in contrast to chemical equilibria containing limited information. Reversible chemical reactions can regenerate the initial substrates from products. In addition, sophisticated thermal inputs can be manipulated by reversal during the chemical reactions before reaching chemical equilibrium. Sigmoidal relationship and kinetics provide bistability between two interconvertible rested metastable states and can exert large differences in their concentrations. Metastable states out of chemical equilibrium exhibit memory effect and future prediction. Positive feedback by self-catalytic chemical reactions provides the amplification of thermal responses by concentration. The involvement of competitive chemical reactions enhances diversity of processing. The fine-tuning of chemical reactions through the modification of molecular and molecular assembly structures broadens the applicable temperature ranges of monitoring. We consider these as the chemical bases for the properties of chemical reactions in thermal input/concentration output systems. They may not be exclusive, and other bases can also be conceivable. Chemical reactions with such properties are not common, and their development and understanding of their properties are interesting subjects in chemistry.

The experimental properties of thermal input/concentration output systems processed by chemical reactions are provided in subsequent sections. Thermal inputs are discussed, such as low or high temperature (Section 5.1), cooling or heating states (Section 5.2), slow or fast cooling and heating states (Section 5.3), cooling history (Section 5.4), and concentration threshold (Section 6). The interfacing of such concentration outputs to other systems is described. Additional discussions on the interfacing are provided in terms of (1) the amplification of small concentration differences by concentration threshold phenomenon (Section 6) and (2) selective binding of the product with receptor or allosteric catalysts (Section 7).

Helicene oligomers with sulfoneamide (S), acetylene (E), aminomethylene (A), and oxymethylene (O) linkers (Figure 9) have been developed, in which S, E, A, and O indicate the linker structures (Figure 10) [29-31,52,53]. These oligomers form homo-double-helix at low temperatures and two molecules of random coils at high temperature. The mixtures of different structures of oligomers containing enantiomeric helicenes form hetero-doublehelixes with enantiomeric right-handed and left-handed helical senses at low temperatures. Their chemical reactions show the following phenomena: heating and cooling induce the reversible formation of double helices in different pathways, which exhibit thermal hysteresis; the formation of double helices involves sigmoidal relationships between temperature and concentration; sigmoidal kinetics appears in the formation of double helices; random coils and double helix involving metastable states form; positive feedback by self-catalytic reactions occurs in the formation of double helices; the formation of hetero-double-helices involves competitive self-catalytic chemical reactions. Detailed experimental results, mechanistic considerations, molecular structures, and self-catalytic chemical reactions are provided in the previous articles [52,53]. This article describes concept and experimental results on thermal input/concentration output systems processed by chemical reactions. 


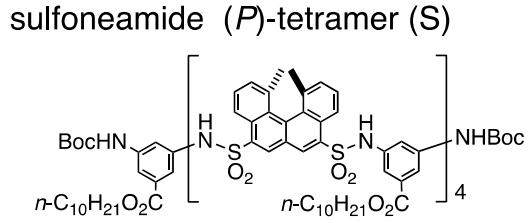

$(P)-1$

oxymethylene $(M)$-oligomers $(\mathrm{O})$

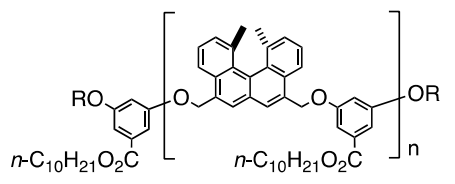

$(M)$-3 $(\mathrm{n}=5) \mathrm{R}=\left(\mathrm{CH}_{2}\right){ }_{16} \mathrm{OCOPh}$ $(M)-4(\mathrm{n}=6) \mathrm{R}=\left(\mathrm{CH}_{2}\right)_{16} \mathrm{OCOPh}$ ethynyl $(M)$-oligomers $(E)$

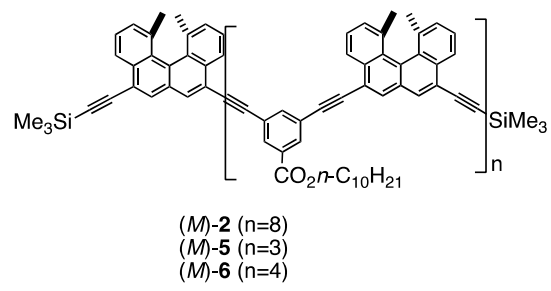

aminomethylene $(M)$-oligomers $(\mathrm{A})$

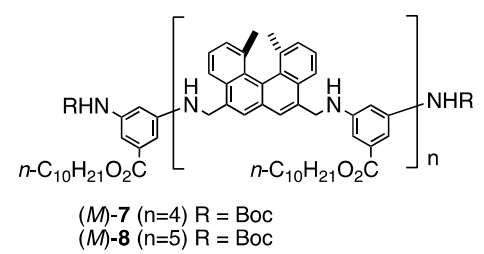

Figure 10. Chemical structures of helicene oligomers.

\section{Thermal Input/Concentration Output Systems Processed by the Chemical Reactions of Helicene Oligomers}

The following sections describe experimental thermal input/concentration output systems processed by the chemical reactions of helicene oligomers. The processing involves reversible chemical reaction $2 \mathbf{A} \mathbf{B}$ between the two oligomers of random coils $2 \mathbf{A}$ and a homo-double-helix B, and 2A and $\mathbf{B}$ form upon heating and cooling, respectively. These chemical reactions proceed out of chemical equilibrium in different pathways during heating and cooling, which is thermal hysteresis, while positive feedback by the self-catalytic reaction $2 \mathbf{A}+\mathbf{B} \rightarrow 2 \mathbf{B}$ is involved and the bistability occurs at different concentrations of $2 \mathbf{A}$ and $\mathbf{B}$ at the same temperature. Outputs are shown by concentration/temperature and concentration/time profiles, in which $\Delta \varepsilon$ obtained by circular dichroism (CD) spectroscopy is considered an equivalent of concentration.

Thermal input/concentration output systems processed by competitive chemical reactions $\mathrm{B} 2 \mathrm{~A} \mathrm{C}$, which involve two different structures of oligomers of randomcoils $2 \mathbf{A}$ containing enantiomeric helicenes and two hetero-double-helices $\mathbf{B}$ and $\mathbf{C}$ with inverted right-handed and left-handed helix senses, are described as follows. Here, 2A and $\mathbf{B} / \mathbf{C}$ form upon heating and cooling, respectively, positive feedback by competitive self-catalytic reactions $2 \mathbf{A}+\mathbf{B} \rightarrow 2 \mathbf{B}$ and $2 \mathbf{A}+\mathbf{C} \rightarrow 2 \mathbf{C}$ is involved and bistability among $2 \mathrm{~A} / \mathbf{B}, 2 \mathrm{~A} / \mathrm{C}$, and $\mathbf{B} / \mathbf{C}$ occurs at the same temperature.

Thermal inputs by stepwise and gradient temperature changes are provided. Stepwise temperature changes are conducted by rapid cooling or heating at a specific temperature. The Peltier device is used for the temperature changes, and the time required to change temperature by several tens of centigrade is approximately $1 \mathrm{~min}$. Rapid temperature changes have faster increase and decrease than chemical reaction rates, and isothermal experiments are expressed by the chemical kinetics. The involvement of self-catalytic chemical reactions exhibits an initial low rate followed by high rate with the progress of the reaction under isothermal conditions, which provides sigmoidal kinetics. This is due to an increase of the products, which are the catalysts.

Thermal inputs by gradient temperature changes at constant rate are also provided. Concentration outputs are affected by the various properties of chemical reactions, which are changed by temperature. The chemical basis for the properties includes reversibility, sigmoidal relationships, sigmoidal kinetics, formation of metastable states, self-catalysis, thermal hysteresis, reaction mechanisms, phase transition by aggregation, and competitive chemical reactions. Thus, diverse bistability in different concentrations of substrates and products is exhibited. Such thermal input/concentration output systems can process 
sophisticated thermal inputs, such as high or low temperature states, cooling or heating states, slow or fast cooling and heating states, and precooling history.

\subsection{High or Low Temperature States}

High and low temperatures are critical to living things $[57,58]$. Our body temperature is maintained at approximately $37^{\circ} \mathrm{C}$ within an error of less than $1{ }^{\circ} \mathrm{C}$, which indicates homeostasis. The thermal inputs of high or low temperatures are processed into concentration outputs through the chemical reactions of proteins. However, the properties of the chemical reactions appear different from those of ordinary chemical equilibria and chemical reactions, which exhibit low sensitivity to small temperature changes under ambient conditions. In the synthetic system of helicene oligomers, temperature threshold phenomenon appears, which sharply responds to a temperature change of $2{ }^{\circ} \mathrm{C}$ and significantly increases the concentrations of products generated by self-catalytic chemical reactions.

Sulfoneamide $(P)$-tetramer $(P)$-1 in 1,3-difluorobenzene $(0.5 \mathrm{mM})$ at $70{ }^{\circ} \mathrm{C}$ containing fully dissociated $2 \mathbf{A}(\mathrm{S})$ was cooled at a rate of $0.25 \mathrm{~K} \mathrm{~min}^{-1}$.[59] When the solution was cooled to $46{ }^{\circ} \mathrm{C}$ and heated, the same cooling and heating curves were obtained in the $\Delta \varepsilon$ /temperature profiles (Figure 11a). When the solution was cooled to $44^{\circ} \mathrm{C}$ and repeatedly heated at $52{ }^{\circ} \mathrm{C}, \Delta \varepsilon$ increased and the curves moved away from the cooling curve reaching $\Delta \varepsilon+150 \mathrm{~cm}^{-1} \mathrm{M}^{-1}$ after the second heating, which indicated the formation of approximately $25 \% \mathbf{B}(\mathrm{S})$. A $2{ }^{\circ} \mathrm{C}$ difference in the first cooling temperatures of $44{ }^{\circ} \mathrm{C}$ and $46{ }^{\circ} \mathrm{C}$ provide considerably different concentrations of $\mathbf{B}(\mathrm{S})$ upon heating. This phenomenon is called the temperature threshold phenomenon. The result is ascribed to the self-catalytic reaction $2 \mathbf{A}(S)+\mathbf{B}(S) \rightarrow 2 \mathbf{B}(S)$, which, once started, does not retard or stop upon cooling and heating (Figure 7). The equilibrium state at $45{ }^{\circ} \mathrm{C}$ is determined as $\Delta \varepsilon+760 \mathrm{~cm}^{-1} \mathrm{M}^{-1}$ by different experiments, and the temperature threshold phenomenon occurs far away from chemical equilibrium. Notably, concentration difference at $44{ }^{\circ} \mathrm{C}$ and $46{ }^{\circ} \mathrm{C}$ experiments is enhanced by repeated temperature changes, which is provided before the completion of a chemical reaction (Figure $4 \mathrm{c}$ ). The large difference in the concentrations of $\mathbf{B}(\mathrm{S})$ may be beneficial for interfacing with other systems (Figure $5 b$ ).

(a)

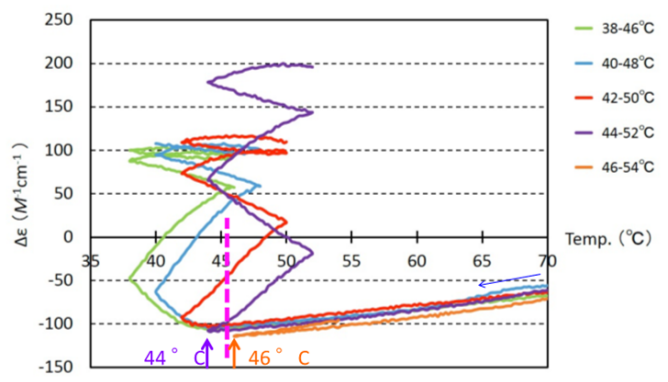

(b)

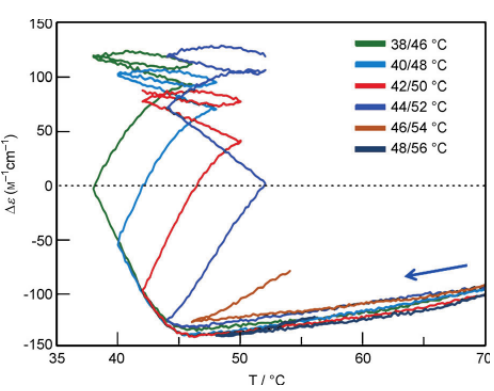

(c)

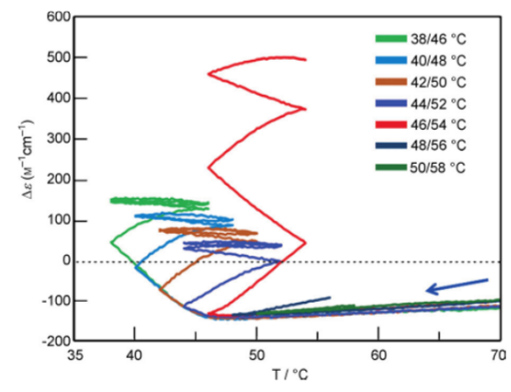

Figure 11. Temperature threshold phenomenon exhibited by $(P) \mathbf{- 1}$ in 1,3-difluorobenzene at a rate of $0.25 \mathrm{~K} \mathrm{~min}^{-1}$ at concentrations of (a) $0.5 \mathrm{mM}$, (b) $0.6 \mathrm{mM}$, and (c) $0.7 \mathrm{mM}$. Reproduced from ref. [59] with permission from Wiley.

At a temperature close to the threshold, significant increase in $\Delta \varepsilon$ occurs after repeated cooling and heating, as shown by a large increase in $\Delta \varepsilon$ in the $44-52{ }^{\circ} \mathrm{C}$ experiment relative to $\Delta \varepsilon$ values in the $42-50{ }^{\circ} \mathrm{C}, 40-48{ }^{\circ} \mathrm{C}$, and $38-46{ }^{\circ} \mathrm{C}$ experiments, which provide a steady state at $\Delta \varepsilon$ of approximately $+100 \mathrm{~cm}^{-1} \mathrm{M}^{-1}$ (Figure 11a). The nonlinear phenomenon is due to self-catalytic chemical reaction, which occurs at a temperature close to the threshold.

Threshold temperature is dependent on concentrations and appears between $46{ }^{\circ} \mathrm{C}$ and $48{ }^{\circ} \mathrm{C}$ at $0.6 \mathrm{mM}$ (Figure 11b) and between $48{ }^{\circ} \mathrm{C}$ and $50{ }^{\circ} \mathrm{C}$ at $0.7 \mathrm{mM}$ (Figure 11c). The results show the fine-tuning of threshold temperature by small changes in conditions, which can be employed for parallel processing (Figure 9). 


\subsection{Cooling or Heating States}

Cooling and heating states are courses of temperature decrease and increase, respectively. Plants exert morning or evening events or spring or autumn events monitoring such states. When a thermometer is used, the monitoring of cooling and heating states requires complex procedures. Temperatures are monitored twice at a time interval and are determined according to increases or decreases in temperature. Using thermal input/concentration output systems processed by chemical reactions, cooling or heating states can be expressed by concentration outputs. This phenomenon exhibits bistability involving metastable states, which converts the analog signals of temperature changing states to the digital signals of concentrations.

\subsubsection{Thermal Hysteresis}

Thermal hysteresis, which provides different curves in concentration (or $\Delta \varepsilon$ )/temperature profiles during cooling and heating, can be used in the processing of cooling and heating states. Temperature is gradually changed at a constant rate between high and low temperatures as inputs, and concentration changes as outputs appear in the different curves in the profiles. Thermal hysteresis is derived from reversible chemical reaction out of chemical equilibrium (Figure $4 b$ ).

$(P)-\mathbf{1}$ shows thermal hysteresis during interconversion of $2 \mathbf{A}(\mathrm{S})$ and $\mathbf{B}(\mathrm{S})$ at high and low temperatures, respectively (Figure 12a) [60]. When $(P)$-1 in 1,3-difluorobenzene $(0.5 \mathrm{mM})$ at $65{ }^{\circ} \mathrm{C}$ with fully dissociated $2 \mathrm{~A}(\mathrm{~S})$ was cooled at a rate of $0.25 \mathrm{~K} \mathrm{~min}^{-1}$, no change in $\Delta \varepsilon-140 \mathrm{~cm}^{-1} \mathrm{M}^{-1}$ occurred down to $40{ }^{\circ} \mathrm{C}$. Subsequent cooling exerted a sharp increase in $\Delta \varepsilon$ by the formation of $\mathbf{B}(\mathrm{S})$, which reached $+490 \mathrm{~cm}^{-1} \mathrm{M}^{-1}$ at $5^{\circ} \mathrm{C}$ with approximately $40 \%$ of $\mathbf{B}(\mathrm{S})$. Heating showed no change in $\Delta \varepsilon$ up to $30^{\circ} \mathrm{C}$, and then $\Delta \varepsilon$ decreased by the formation of $2 \mathrm{~A}(\mathrm{~S})$ at $65{ }^{\circ} \mathrm{C}$. Different cooling and heating curves in the $\Delta \varepsilon /$ temperature profiles showed thermal hysteresis.

(a)

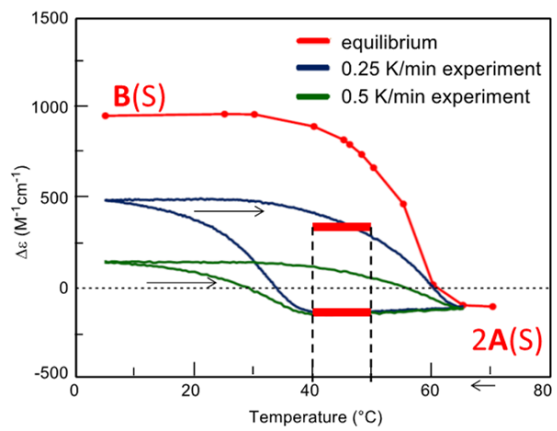

(b)

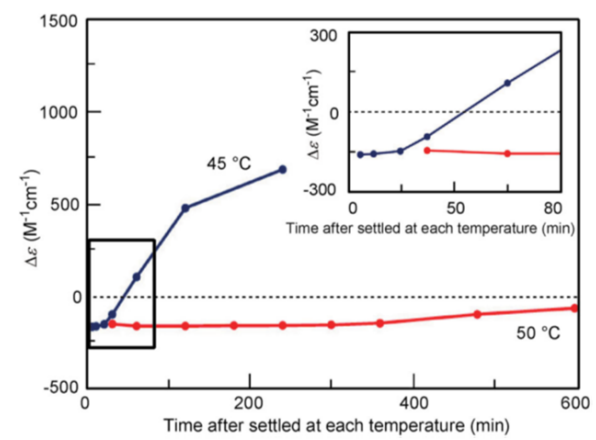

Figure 12. Chemical structures of helicene oligomers. (a) Thermal hysteresis of $(P) \mathbf{- 1}$ in 1 ,3difluorobenzene $(0.5 \mathrm{mM})$. Bold red lines indicate bistability involving metastable states. (b) Sigmoidal kinetics under isothermal conditions of 45 and $50{ }^{\circ} \mathrm{C}$. Reproduced from ref. [60] with permission from Wiley.

The phenomenon of the reversible chemical reaction $2 \mathbf{A} \mathbf{B}$ can be used in determining cooling or heating states. During cooling between $40{ }^{\circ} \mathrm{C}$ and $50{ }^{\circ} \mathrm{C}, \Delta \varepsilon$ value of $-140 \mathrm{~cm}^{-1} \mathrm{M}^{-1}$ indicates fully dissociated $2 \mathrm{~A}(\mathrm{~S})$. During heating between $40^{\circ} \mathrm{C}$ and $50{ }^{\circ} \mathrm{C}$, $\Delta \varepsilon$ of approximately $+400 \mathrm{~cm}^{-1} \mathrm{M}^{-1}$ indicates the formation of approximately $50 \% \mathrm{~B}(\mathrm{~A})$. Bistability with a considerable difference in the concentrations of $2 \mathbf{A}(\mathrm{S})$ and $\mathbf{B}(\mathrm{S})$ appears during cooling and heating between $40^{\circ} \mathrm{C}$ and $50^{\circ} \mathrm{C}$ (Figure 12a, red bold lines). In other words, when significant amounts of $2 \mathrm{~A}(\mathrm{~S})$ are formed between $40^{\circ} \mathrm{C}$ and $50{ }^{\circ} \mathrm{C}$, it shows the cooling state of $(P)-1$. When approximately $50 \% \mathbf{B}(\mathrm{S})$ is formed, it shows the heating state. Both states are beyond chemical equilibrium (Figure 12a). 
The cooling curve shows the sigmoidal relationship out of equilibrium (Figure 12a), which involves slow bimolecular chemical reaction $2 \mathbf{A}(S) \rightarrow \mathbf{B}(S)$ above $40{ }^{\circ} \mathrm{C}$, rapid selfcatalytic chemical reaction $2 \mathbf{A}(S)+\mathbf{B}(S) \rightarrow 2 \mathbf{B}(S)$ below $40{ }^{\circ} \mathrm{C}$, and retardation of chemical reactions below $20{ }^{\circ} \mathrm{C}$ (Figure 12a). The flat domain at $\Delta \varepsilon$ of $-140 \mathrm{~cm}^{-1} \mathrm{M}^{-1}$ between $40{ }^{\circ} \mathrm{C}$ and $50{ }^{\circ} \mathrm{C}$ during cooling indicates the stabilized metastable state of dissociated $2 \mathbf{A}(\mathrm{S})$. The heating curve also shows sigmoidal relationship with a small increment at $\Delta \varepsilon$ of approximately $+400 \mathrm{~cm}^{-1} \mathrm{M}^{-1}$, which indicates a stabilized metastable state of approximately $40 \% 2 \mathrm{~A}(\mathrm{~S})$ between $40{ }^{\circ} \mathrm{C}$ and $50{ }^{\circ} \mathrm{C}$. Then, bistability occurs at the temperature range (Figure 6b).

Sigmoidal kinetic appears under isothermal conditions and provides the stabilized metastable states of $2 \mathrm{~A}(\mathrm{~S})$ at the initial $30 \mathrm{~min}$ at $40{ }^{\circ} \mathrm{C}$ and $400 \mathrm{~min}$ at $50{ }^{\circ} \mathrm{C}$ (Figures $6 \mathrm{c}$ and $12 b)$.

A possible application of the cooling state of this system is flower blossoms in a summer afternoon. A significant amount of $2 \mathbf{A}(\mathrm{S})$ is formed in the afternoon of a very hot summer between $40^{\circ} \mathrm{C}$ and $50^{\circ} \mathrm{C}$ during a rapid cooling at a rate of $0.25 \mathrm{~K} \mathrm{~min}^{-1}\left(15 \mathrm{~K} \mathrm{~h}^{-1}\right)$. Then, the system processes an input of cooling state to form a high concentration of $2 \mathrm{~A}(\mathrm{~S})$, which can be interfaced with other systems and eventually makes flowers in the real world. It does not occur in the morning during heating, because the concentration of $2 \mathbf{A}(S)$ is low. An advantage of this system is that the temperature change state is processed into a concentration output, which involves bistability with large differences in the concentrations of $2 \mathbf{A}(S)$ and $\mathbf{B}(S)$ at the same temperature range (Figures $6 \mathrm{~b}$ and $12 \mathrm{a}$ ). Large differences in the three-dimensional molecular structures of random-coils $2 \mathrm{~A}(\mathrm{~S})$ and homo-double-helix B(S) may be beneficial for interfacing.

Temperature change rate affects the thermal hysteresis of $(P)-\mathbf{1}$, and a smaller hysteresis area is obtained at a rate of $0.5 \mathrm{~K} \mathrm{~min}^{-1}$ compared with $0.25 \mathrm{~K} \mathrm{~min}^{-1}$. A metastable state with $\Delta \varepsilon$ of $+150 \mathrm{~cm}^{-1} \mathrm{M}^{-1}$ at $5{ }^{\circ} \mathrm{C}$ is obtained at a rate of $0.5 \mathrm{~K} \mathrm{~min}^{-1}$, in contrast to the metastable state with $\Delta \varepsilon$ of $+490 \mathrm{~cm}^{-1} \mathrm{M}^{-1}$ at $5^{\circ} \mathrm{C}$ at a rate of $0.25 \mathrm{~K} \mathrm{~min}^{-1}$ (Figure 12a). Thus, metastable states at low temperatures can be fine-tuned by the cooling rate for parallel processing (Figure 9). Much faster temperature changes likely provide a straight line at $\Delta \varepsilon$ of $-140 \mathrm{~cm}^{-1} \mathrm{M}^{-1}$ during cooling and heating, in which no formation of $\mathbf{B}(\mathrm{S})$ occurs. The reason is that the temperature change rate is significantly larger than the rate of the chemical reactions 2A B. Much slower temperature change provides an identical cooling and heating curve, which coincides with the equilibrium curve.

The formation of metastable $2 \mathrm{~A}(\mathrm{~S})$ during cooling between $40{ }^{\circ} \mathrm{C}$ and $50{ }^{\circ} \mathrm{C}$ contains a memory at high temperatures. The metastable $2 \mathrm{~A}(\mathrm{~S})$ between $40{ }^{\circ} \mathrm{C}$ and $50{ }^{\circ} \mathrm{C}$ is converted into $\mathbf{B}(\mathrm{S})$ under chemical equilibrium, and the metastable state contains a prediction to form $\mathbf{B}(S)$.

\subsubsection{Equilibrium Crossing}

Equilibrium crossing is a phenomenon in which a chemical reaction proceeds in a way that substantially exceeds a state of chemical equilibrium. The phenomenon involves significant acceleration of chemical reaction $2 \mathbf{A}(\mathrm{E}) \rightarrow \mathbf{B}(\mathrm{E})$ by self-catalytic chemical reaction $2 \mathbf{A}(\mathrm{E})+\mathbf{B}(\mathrm{E}) \rightarrow \mathbf{2} \mathbf{B}(\mathrm{E})$. Ethynyl $(M)$-nonamer $(M)-2$ exhibits equilibrium crossing during the formation of $\mathbf{B}(\mathrm{E})$ (Figure 13a) [61]. (M)-2 in toluene (0.1 mM) was cooled and heated between $95{ }^{\circ} \mathrm{C}$ and $5{ }^{\circ} \mathrm{C}$ at a rate of $1.0 \mathrm{~K} \mathrm{~min}^{-1}$, in which the twofold downward inflation of $\Delta \varepsilon$ during heating indicates the formation of $\mathbf{B}(\mathrm{E})$. As a result, distorted hysteresis curves are obtained by reversible chemical reaction $2 \mathrm{~A}(\mathrm{E}) \quad \mathbf{B}(\mathrm{E})$. Notably, heating increases $\mathbf{B}(\mathrm{E})$ (Figure $6 c$ ), which is due to the self-catalytic chemical reaction $2 \mathbf{A}(E)+\mathbf{B}(E) \rightarrow 2 \mathbf{B}(E)$. Thus, the heating curve crosses the equilibrium curve upon heating, and an energetically uphill chemical reaction $2 \mathbf{A}(\mathrm{E}) \rightarrow \mathbf{B}(\mathrm{E})$ occurs. The phenomenon is compared with $(P)-\mathbf{1}$, by which self-catalytic reaction $2 \mathbf{A}(S)+\mathbf{B}(S) \rightarrow 2 \mathbf{B}(S)$ occurs during cooling (Figures $6 \mathrm{~b}$ and $12 \mathrm{a}$ ). 
(a)

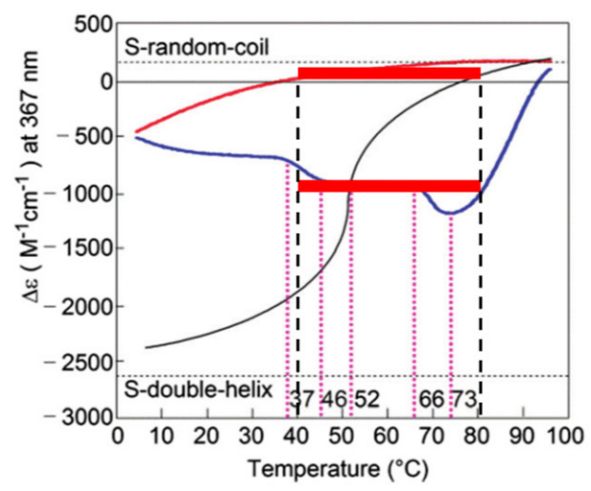

(b)

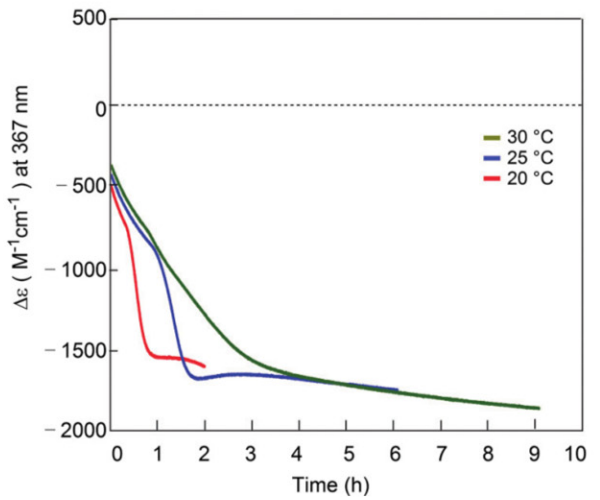

Figure 13. (a) Thermal hysteresis of $(M)-2$ in toluene $(0.1 \mathrm{mM})$ between 95 and $5{ }^{\circ} \mathrm{C}$ at a rate of $1.0 \mathrm{~K} \mathrm{~min}^{-1}$. Black line shows equilibrium curve, and red bold lines indicate bistability involving metastable states. (b) Distorted sigmoidal kinetics under isothermal conditions. Reproduced from ref. [61].

Also note that distorted sigmoidal kinetics appears under isothermal conditions, which involves abrupt increases in $\mathbf{B}(\mathrm{E})$ at the intermediate state (Figure 13b).

Bistability with a large difference in the concentration of $\mathbf{B}(\mathrm{E})$ appears in a broad range between $40^{\circ} \mathrm{C}$ and $80^{\circ} \mathrm{C}$ at the same temperatures (Figure 13a, red bold lines), which is different from $(P)-\mathbf{1}$ in a short range (Figure 12a, red bold lines). The bistability of $2 \mathbf{A}(\mathrm{E})$ and $\mathbf{B}(\mathrm{E})$ with $\Delta \varepsilon$ of approximately $0 \mathrm{~cm}^{-1} \mathrm{M}^{-1}$ and $-1000 \mathrm{~cm}^{-1} \mathrm{M}^{-1}$ indicates the exclusive formation of $2 \mathrm{~A}(\mathrm{E})$ without a formation of $\mathbf{B}(\mathrm{E})$ upon cooling, but with a formation of approximately $40 \% \mathbf{B}(\mathrm{E})$ upon heating (Figure 13a, red bold lines). The large difference in the concentrations may be beneficial for effective interfacing and discriminating between cooling and heating states (Figure $6 \mathrm{~b}$ ). Changes in the oligomer structure of $(P)-\mathbf{1}$ and $(M)-\mathbf{2}$ can fine-tune the nature of bistability for parallel processing (Figure 9).

\subsubsection{Aggregation to Form Organogels and Vesicles}

Thermal input/concentration output systems processed by chemical reactions can involve the aggregation of double-helix $\mathbf{B}$ by the reversible sequential chemical reactions $2 \mathbf{A} \mathbf{B} \mathbf{B}_{\mathrm{n}}$, in which $\mathbf{B}_{\mathrm{n}}$ indicates aggregates with ordered structures. Such systems provide concentration outputs by the reversible chemical reaction $2 \mathbf{A} \mathbf{B}$ and subsequent reversible aggregation to form $\mathbf{B}_{\mathrm{n}}$, which exhibit thermal hysteresis.

A mixture of oxymethylene $(P)$-pentamer $(P)-3$ and $(M)$-hexamer $(M)-4$ with terminal $\mathrm{C}_{16}$ alkyl groups in trifluoromethylbenzene $(2.0 \mathrm{mM})$ containing fully dissociated $2 \mathrm{~A}(\mathrm{O})$ at $90{ }^{\circ} \mathrm{C}$ was cooled and heated between $5^{\circ} \mathrm{C}$ at a rate of $0.1 \mathrm{~K} \mathrm{~min}^{-1}$ [62]. A sharp decrease in $\Delta \varepsilon$ occurred during cooling below $20^{\circ} \mathrm{C}$, which reached approximately $-250 \mathrm{~cm}^{-1} \mathrm{M}^{-1}$ at $5^{\circ} \mathrm{C}$, providing $\mathbf{B}(\mathrm{O})$ and $\mathbf{B}(\mathrm{O})_{n}$ (Figure 14). $\mathbf{B}(\mathrm{O})$ aggregates to form organogels $\mathbf{B}(\mathrm{O})_{\mathrm{n}}$ containing concentric vesicles and solidifies the solution. A sharp increase in $\Delta \varepsilon$ occurs upon heating to above $40{ }^{\circ} \mathrm{C}$, which exhibits thermal hysteresis with different cooling and heating curves. Heating and cooling states are discriminated by $\Delta \varepsilon$ at approximately $-250 \mathrm{~cm}^{-1} \mathrm{M}^{-1}$ and $0 \mathrm{~cm}^{-1} \mathrm{M}^{-1}$, respectively, between $25^{\circ} \mathrm{C}$ and $50{ }^{\circ} \mathrm{C}$ (Figure 14, red bold lines). The absence of $\mathbf{B}(\mathrm{O})$ is an indication of a cooling state, and the formation of considerable amounts of $\mathbf{B}(\mathrm{O})$ and $\mathbf{B}(\mathrm{O})_{n}$ are indications of a heating state. Sharp decrease and increase in $\Delta \varepsilon$ with a sigmoidal relationship are notable properties of the system processed by reversible sequential chemical reactions $2 \mathrm{~A}(\mathrm{O}) \mathbf{B}(\mathrm{O}) \mathbf{B}(\mathrm{O})_{\mathrm{n}}$, which is different from the modest increment in the decrease and increase of $(P)-\mathbf{1}$ (Figure 12a). Bistability appears with large differences in the concentrations of $\mathbf{B}(\mathrm{O})$ between $25^{\circ} \mathrm{C}$ and $50{ }^{\circ} \mathrm{C}$ at the same temperature range (Figure $6 \mathrm{~b}$ ). In addition, the three-dimensional molecular and molecular assembly structures of the organogels and concentric vesicles $\mathbf{B}(\mathrm{O})_{\mathrm{n}}$ are considerably different from those of $2 \mathrm{~A}(\mathrm{O})$, which may be beneficial for interfacing. Thermal 
hysteresis does not appear at a rate of $5 \mathrm{~K} \mathrm{~min}^{-1}$ because the temperature change is much faster than the chemical reactions.

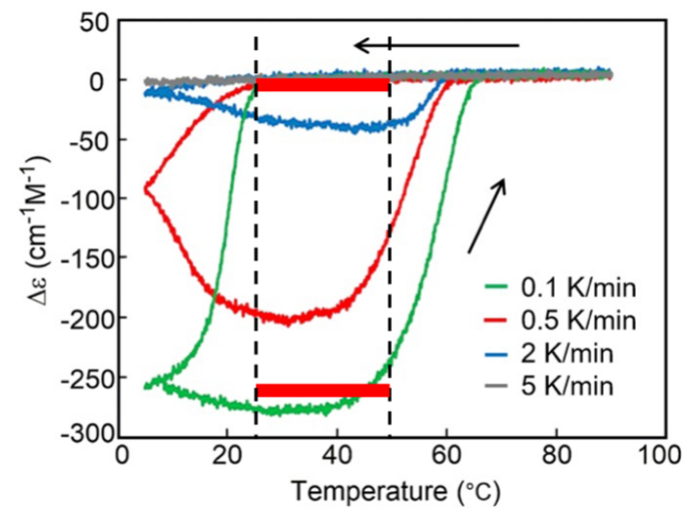

Figure 14. Thermal hysteresis of $(P)-3$ and $(M)-4$ in toluene $(2.0 \mathrm{mM})$ between 90 and $5{ }^{\circ} \mathrm{C}$. Red bold lines indicate bistability involving metastable states. Reproduced from ref. [62] with permission from Chemical Society of Japan.

\subsubsection{Aggregation to Form Organogels with Stepwise Relationship and Kinetics}

Another input/output system processed by reversible sequential chemical reactions $2 \mathbf{A}=\mathbf{B}_{\mathrm{n}}$ provides different concentration outputs in the formation of organogels, exhibiting stepwise sigmoidal relationships and kinetics with an intermediate metastable state [63].

A mixture of ethynyl $(M)$-tetramer $(M)-5$ and $(P)$-pentamer $(P)-6$ in toluene $(0.5 \mathrm{mM})$ forms hetero-double-helix $\mathbf{B}(\mathrm{E})$ and organogel $\mathbf{B}(\mathrm{E})_{\mathrm{n}}$. Fully dissociated $2 \mathrm{~A}(\mathrm{E})$ at $80^{\circ} \mathrm{C}$ was cooled and heated between $5^{\circ} \mathrm{C}$ at a rate of $2.0 \mathrm{~K} \mathrm{~min}^{-1}$ (Figure 15a, blue lines) [64]. Upon cooling, $\Delta \varepsilon$ started to increase at $55^{\circ} \mathrm{C}$ and reached $+620 \mathrm{~cm}^{-1} \mathrm{M}^{-1}$ at $5{ }^{\circ} \mathrm{C}$. Heating at the same rate decreased $\Delta \varepsilon$, and a plateau appeared between $50{ }^{\circ} \mathrm{C}$ and $60{ }^{\circ} \mathrm{C}$ at $\Delta \varepsilon$ of approximately $+150 \mathrm{~cm}^{-1} \mathrm{M}^{-1}$. The phenomenon is due to the involvement of sequential self-catalytic chemical reactions $2 \mathbf{A}(E)+\mathbf{B}(E) \rightarrow 2 \mathbf{B}(E)$ and $2 \mathbf{A}(E)+\mathbf{B}(E)_{n} \rightarrow \mathbf{B}(E)_{n}$. Bistability between $50{ }^{\circ} \mathrm{C}$ and $60{ }^{\circ} \mathrm{C}$ appears in the cooling state containing exclusive $2 \mathrm{~A}(\mathrm{E})$ and in the heating state containing $\mathbf{B}(\mathrm{E})$ (Figure 15a, red bold lines), in which $2 \mathrm{~A}(\mathrm{E})$ is metastable. Change in the rate to 0.5 and $2.0 \mathrm{~K} \mathrm{~min}^{-1}$ shows a plateau upon heating at the same $\Delta \varepsilon$ and temperature range, indicating the stable nature of the $\mathbf{B}(\mathrm{E})$.

(a)

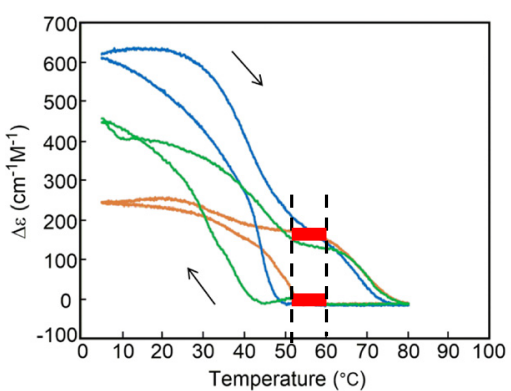

(b)

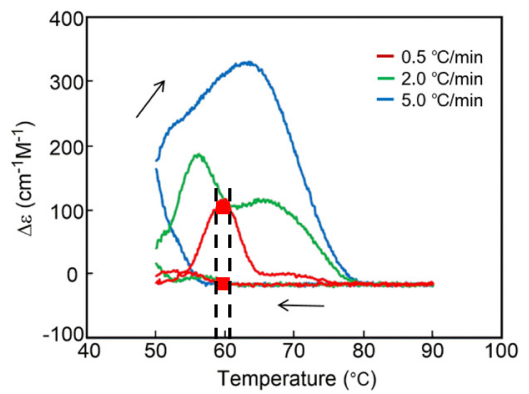

(c)

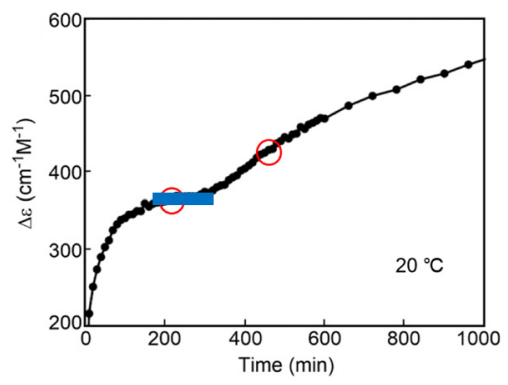

Figure 15. (a) Thermal hysteresis of $(M)-5$ and $(P)-6$ in toluene $(0.5 \mathrm{mM})$ between 80 and $5{ }^{\circ} \mathrm{C}$ at rates of 0.5 (yellow), 2.0 (blue), and 3.0 (green) $\mathrm{K} \mathrm{min}^{-1}$. (b) Thermal hysteresis between $90{ }^{\circ} \mathrm{C}$ and $50{ }^{\circ} \mathrm{C}$ at rates of $0.5,2.0$, and $5.0 \mathrm{~K} \mathrm{~min}^{-1}$. (c) Chemical kinetics at $20^{\circ} \mathrm{C}$. Red bold lines indicate bistability. Red circles indicate inflection points. Blue bold line indicates metastable state. Reproduced from ref. [62] with permission from Wiley. 
Stepwise sigmoidal kinetics at $2{ }^{\circ} \mathrm{C}$ provides a metastable state with $\Delta \varepsilon$ of $360 \mathrm{~cm}^{-1} \mathrm{M}^{-1}$ at an intermediate time (Figure $15 \mathrm{c}$, red bold line). The involvement of intermediate states is a characteristic feature of this thermal input/concentration output system processed by the reversible sequential chemical reactions $2 \mathrm{~A}(\mathrm{E}) \mathrm{B}(\mathrm{E}) \mathrm{B}(\mathrm{E})_{\mathrm{n}}$.

At a different temperature range, thermal hysteresis appears in a narrow temperature range, which determines a specific temperature during heating. Fully dissociated $2 \mathrm{~A}(\mathrm{E})$ was cooled and heated between 90 and $50{ }^{\circ} \mathrm{C}$ at a rate of $5.0 \mathrm{~K} \mathrm{~min}^{-1}$ (Figure 15b, red line). No change was observed during cooling to $50^{\circ} \mathrm{C}$, and a bell-shaped curve appeared at the maximum $\Delta \varepsilon$ at $60{ }^{\circ} \mathrm{C}$ during heating (Figure $6 \mathrm{c}$ ). Significant acceleration by self-catalytic reactions $2 \mathbf{A}(E)+\mathbf{B}(E) \rightarrow 2 \mathbf{B}(E)$ and $2 \mathbf{A}(E)+\mathbf{B}(E)_{n} \rightarrow \mathbf{B}(E)_{n}$ occurs during heating but not during cooling. The specific temperature of $60^{\circ} \mathrm{C}$ is then determined during heating, which involves bistability between $2 \mathbf{A}(\mathrm{E})$ and $\mathbf{B}(\mathrm{E}) / \mathbf{B}(\mathrm{E})_{\mathrm{n}}$ (Figure $15 \mathrm{~b}$, red bold lines). Large differences in the concentrations of $2 A(E)$ and $\mathbf{B}(E) / \mathbf{B}(E)_{n}$ appears at the same temperature range. Also note that $\mathbf{B}(\mathrm{E})$ aggregates to form organogel $\mathbf{B}(\mathrm{E})_{n}$, which solidifies the solution. Then, different three-dimensional structures of $2 \mathbf{A}(\mathrm{E})$ and polymeric $\mathbf{B}(\mathrm{E})_{\mathrm{n}}$, the latter of which solidifies the solution and changes mechanical property of the molecular assembly, may be beneficial for interfacing.

Other thermal hysteresis curves are obtained at different rates: two maximum $\Delta \varepsilon$ values at $56{ }^{\circ} \mathrm{C}$ and $66^{\circ} \mathrm{C}$ were observed under $2.0 \mathrm{~K} \mathrm{~min}^{-1}$ and the maximum $\Delta \varepsilon$ at $64{ }^{\circ} \mathrm{C}$ under $0.5 \mathrm{~K} \mathrm{~min}^{-1}$. Then, the specific temperature during heating can be fine-tuned by conditions, which is beneficial for parallel processing (Figure 9).

\subsection{Fast or Slow Cooling States}

Monitoring fast or slow temperature changes is critical to living things. For example, plants can discriminate between spring and morning, both of which are heating states but have different rates. Thermal input/concentration output systems processed by competitive chemical reactions $2 \mathbf{A} \rightarrow \mathbf{B}$ and $2 \mathbf{A} \rightarrow \mathbf{C}$ can be used in monitoring temperature change rates by converting slow or fast cooling states to the concentrations of $\mathbf{A}, \mathbf{B}$, and $\mathbf{C}$.

Mixtures of aminomethylene $(P)$-tetramer $(P)$-7 and $(M)$-pentamer $(M)$-8 form heterodouble-helices $\mathbf{B}(\mathrm{A})$ and $\mathbf{C}(\mathrm{A})$ with the inverted right-handed and left-handed helix senses, which provide negative and positive $\Delta \varepsilon$, respectively, with comparable intensity.[65] The formation of $\mathbf{B}(\mathrm{A}), \mathbf{C}(\mathrm{A})$, and random-coil $2 \mathrm{~A}(\mathrm{~A})$ occurs by reversible competitive chemical reactions $2 \mathrm{~A}(\mathrm{~A}) \quad \mathrm{B}(\mathrm{A}) \quad \mathrm{C}(\mathrm{A})$ involving two competitive self-catalytic reactions $2 \mathbf{A}(E)+\mathbf{B}(E) \rightarrow 2 \mathbf{B}(E)$ and $2 \mathrm{~A}(\mathrm{E})+\mathbf{C}(\mathrm{E}) \rightarrow 2 \mathrm{C}(\mathrm{E})$. At high temperatures, $2 \mathrm{~A}(\mathrm{~A})$ is thermodynamically the most stable. At low temperatures, $C(A)$ is the most stable. $B(A)$ is metastable at both temperatures. The thermal input/concentration output system exhibits complex bistability phenomena. The system provides either structured $\mathbf{B}(A)$ or $\mathbf{C}(A)$ as the major product at the same temperature because of the difference in temperature dependency among the competitive self-catalytic chemical reactions. Ordinary bimolecular competitive reactions do not generally switch major products through temperature changes unless the mechanisms change, as noted in Section 3.4.

Stepwise thermal input exerts three-state one-directional structure change through sequential chemical reactions $2 \mathrm{~A}(\mathrm{~A}) \rightarrow \mathbf{B}(\mathrm{A}) \rightarrow \mathbf{C}(\mathrm{A})$. A mixture of $(P)-7$ and $(M)-8$ in fluorobenzene $(1 \mathrm{mM})$ was heated to $70{ }^{\circ} \mathrm{C}$ to form fully dissociated $2 \mathrm{~A}(\mathrm{~A})$, which was rapidly cooled to $25{ }^{\circ} \mathrm{C}$ and allowed to settle. The $\Delta \varepsilon$ / time profiles showed a rapid decrease in $\Delta \varepsilon$ at $25^{\circ} \mathrm{C}$, forming metastable $\mathbf{B}(\mathrm{A})$ (Figure $16 \mathrm{~b}$ ), which was then slowly converted into $\mathbf{C}(\mathrm{A})$ under chemical equilibrium in $73 \mathrm{~h}$ (Figure 16a). Three states, $2 \mathbf{A}(\mathrm{A}), \mathbf{B}(\mathrm{A})$, and $\mathbf{C}(\mathrm{A})$ appeared under an isothermal condition. When $\mathrm{C}(\mathrm{A})$ was heated to $70{ }^{\circ} \mathrm{C}, 2 \mathrm{~A}(\mathrm{~A})$ was regenerated. The phenomenon involved reversible chemical reactions $2 \mathrm{~A}(\mathrm{~A}) \mathrm{B}(\mathrm{A}) \mathrm{C}(\mathrm{A})$ out of chemical equilibrium. 
(a)

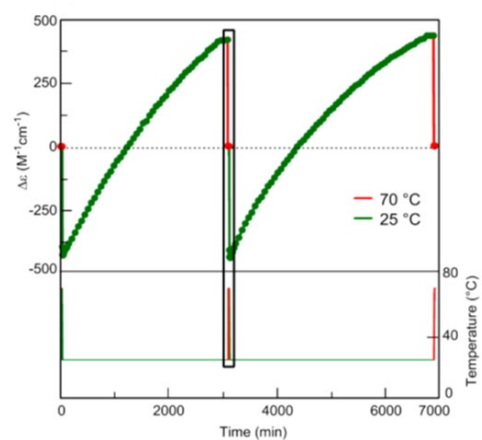

(b)

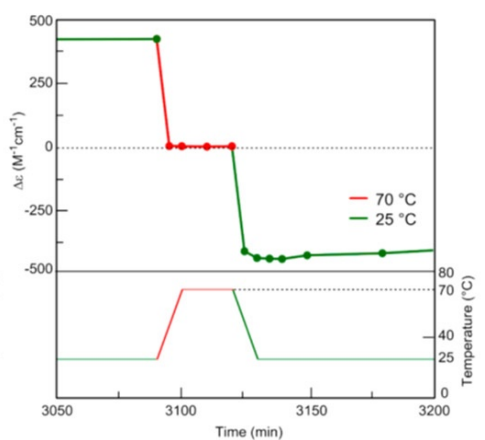

(c)

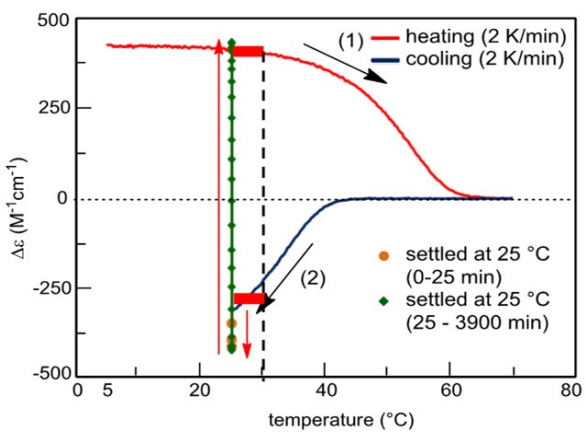

Figure 16. (a) Three-state one-directional structure change of $(P)-7$ and $(M)-8$ in fluorobenzene $(1 \mathrm{mM})$ by heating to $70{ }^{\circ} \mathrm{C}$ and cooling to $25^{\circ} \mathrm{C}$. (b) Expansion of (a) in the square. (c) Thermal hysteresis of $(P)-\mathbf{1}$ and $(M)-\mathbf{2}$ in fluorobenzene $(0.5 \mathrm{mM})$ obtained through heating to $5-70{ }^{\circ} \mathrm{C}$, cooling to $70-25^{\circ} \mathrm{C}$, and settling at $25^{\circ} \mathrm{C}$. Red bold lines indicate bistability. Reproduced from ref. [65] with permission of the American Chemical Society.

Thermal hysteresis appears as shown by $\Delta \varepsilon$ /temperature profiles (Figure 16c). The heating of $\mathrm{C}(\mathrm{A})$ from 5 to $70{ }^{\circ} \mathrm{C}$ at a rate of $2 \mathrm{~K} \mathrm{~min}^{-1}$ provides $2 \mathrm{~A}(\mathrm{~A})$ with $\Delta \varepsilon$ of approximately $0 \mathrm{~cm}^{-1} \mathrm{M}^{-1}$. Then, $2 \mathrm{~A}(\mathrm{~A})$ was cooled to $25^{\circ} \mathrm{C}$ at the same rate and allowed to settle at the same temperature. The $\Delta \varepsilon$ decreased to $-310 \mathrm{~cm}^{-1} \mathrm{M}^{-1}$, and an overshoot to $-430 \mathrm{~cm}^{-1} \mathrm{M}^{-1}$ and increase of $+430 \mathrm{~cm}^{-1} \mathrm{M}^{-1}$ were observed in $73 \mathrm{~h}$. The bistability of $\mathbf{B}(\mathrm{A})$ and $\mathrm{C}(\mathrm{A})$ was observed at $25^{\circ} \mathrm{C}$, along with a large difference in concentrations and three-dimensional structures, which may be beneficial for interfacing (Figure 16c, red bold lines).

Another thermal hysteresis appears by the interconversion of $2 \mathrm{~A}(\mathrm{~A})$ and $\mathbf{B}(\mathrm{A})$ as temperature decreases and increases between $70{ }^{\circ} \mathrm{C}$ and $5{ }^{\circ} \mathrm{C}$ at a constant rate (Figure 17a). Cooling of fully dissociated $2 \mathrm{~A}(\mathrm{~A})$ from $70^{\circ} \mathrm{C}$ to $40^{\circ} \mathrm{C}$ at a rate of $2 \mathrm{~K} \mathrm{~min}^{-1}$ did not change $\Delta \varepsilon\left(0 \mathrm{~cm}^{-1} \mathrm{M}^{-1}\right)$. The $\Delta \varepsilon$ value decreased to $-430 \mathrm{~cm}^{-1} \mathrm{M}^{-1}$ at $5{ }^{\circ} \mathrm{C}$, and approximately $50 \% \mathrm{~B}(\mathrm{~A})$ was produced. Heating from $5^{\circ} \mathrm{C}$ to $30^{\circ} \mathrm{C}$ did not change $\Delta \varepsilon$, which increased generating $2 \mathrm{~A}(\mathrm{~A})$ at $60^{\circ} \mathrm{C}$. Bistability was observed between $40{ }^{\circ} \mathrm{C}$ and $50{ }^{\circ} \mathrm{C}$ by the formation of $2 \mathbf{A}(\mathrm{A})$ during cooling and the formation of approximately $50 \% \mathbf{B}(\mathrm{A})$ during heating, both of which are metastable (Figure 17a, red bold lines). The cooling and heating states were exhibited by $2 \mathbf{A}(\mathrm{A})$ and $\mathbf{B}(\mathrm{A})$, respectively, which showed large differences in concentrations and three-dimensional structures. The flat domains at low temperatures stabilized metastable B(A), which was out of chemical equilibrium (Figure $6 \mathrm{~b}$ ).

(a)

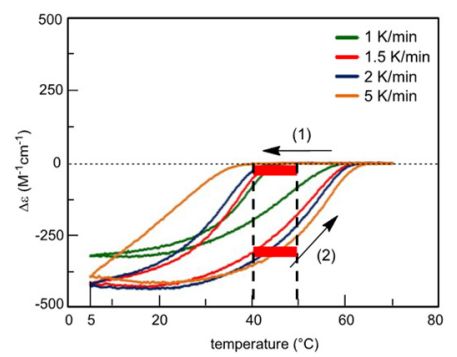

(b)

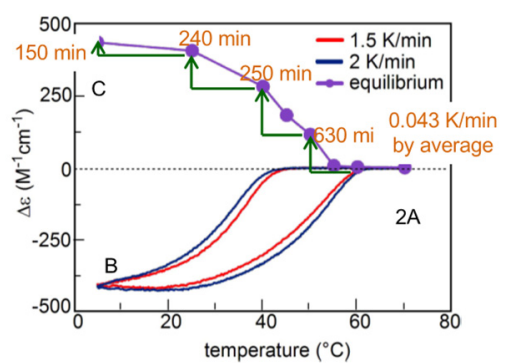

(c)

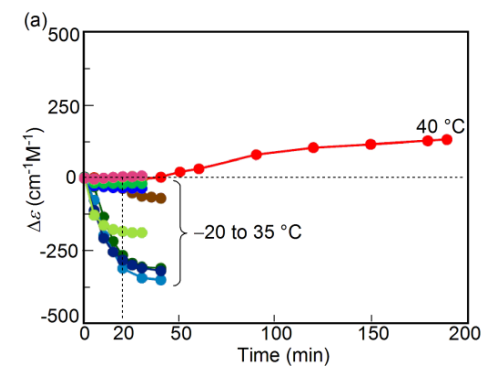

Figure 17. Cont. 
(d)

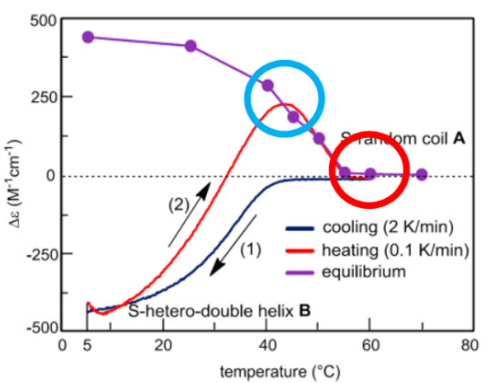

(e)

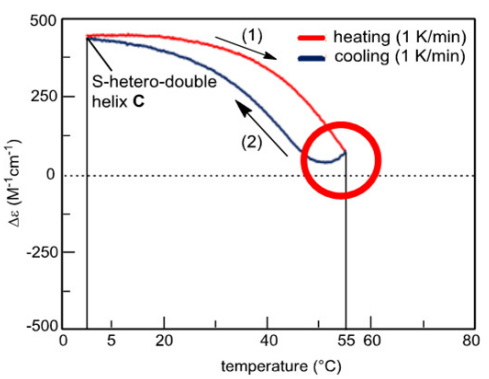

Figure 17. (a) Thermal hysteresis of $(P)-7$ and $(M)-8$ in fluorobenzene $(0.5 \mathrm{mM})$ after cooling and heating between $70{ }^{\circ} \mathrm{C}$ and $5{ }^{\circ} \mathrm{C}$. (b) Slow cooling at an average rate of $0.043 \mathrm{~K} \mathrm{~min}^{-1}$ (purple line). For comparison, results in (a) are reproduced. (c) Sigmoidal kinetics of chemical reaction $2 \mathrm{~A}(\mathrm{~A}) \rightarrow \mathbf{B}(\mathrm{A})$ at $40{ }^{\circ} \mathrm{C}$ [66]. (d) Thermal hysteresis between $60^{\circ} \mathrm{C}$ and $5{ }^{\circ} \mathrm{C}$ during cooling at a rate of $2 \mathrm{~K} \mathrm{~min}^{-1}$ and heating at a rate of $0.1 \mathrm{~K} \mathrm{~m}^{-1}$. (e) Thermal hysteresis between $55^{\circ} \mathrm{C}$ and $5{ }^{\circ} \mathrm{C}$ by heating and cooling at a rate of $1 \mathrm{~K} \mathrm{~min}^{-1}$. Red bold line indicates bistability. Blue circle indicates specific temperature during heating. Red circles indicate effects of temperature range by a difference of $5^{\circ} \mathrm{C}$. Reproduced from ref. [65] with permission of the American Chemical Society.

A small effect of temperature change rate appears between 1 and $5 \mathrm{~K} \mathrm{~min}-1$ (Figure 17a), which shows a broader applicability of $(P)-7 /(M)-8$ in the rate compared with $(P)-\mathbf{1}$ (Figure 12a). The metastable 2A(A) and $\mathbf{B}(\mathrm{A})$ have long lifetimes due to the sigmoidal relationship and may be beneficial for interfacing with other systems. Also note that the metastable state $\mathbf{B}(\mathrm{A})$ at $25^{\circ} \mathrm{C}$ contains memory that $\mathbf{B}(\mathrm{A})$ was cooled from $2 \mathrm{~A}(\mathrm{~A})$ under the condition. $\mathbf{B}(\mathrm{A})$ under an isothermal condition will be converted to $\mathrm{C}(\mathrm{A})$ through the inversion of the helical sense, which predicts the formation of $C(A)$ from $B(A)$.

A very slow cooling of $2 \mathrm{~A}(\mathrm{~A})$ provides $\mathrm{C}(\mathrm{A})$ to exhibit a curve close to chemical equilibrium (Figure $17 \mathrm{~b}$, purple line). When $2 \mathrm{~A}(\mathrm{~A})$ at $70{ }^{\circ} \mathrm{C}$ was cooled to $5{ }^{\circ} \mathrm{C}$ in a repetitively stepwise manner at an average rate of $0.043 \mathrm{~K} \mathrm{~min}^{-1}, \Delta \varepsilon$ increased to $+430 \mathrm{~cm}^{-1} \mathrm{M}^{-1}$ at $5{ }^{\circ} \mathrm{C}$ by forming $\mathrm{C}(\mathrm{A})$ without forming $\mathbf{B}(\mathrm{A})$ (Figure $17 \mathrm{~b}$ ). Thus, slow cooling provides $\mathrm{C}(\mathrm{A})$ from $2 \mathrm{~A}(\mathrm{~A})$ and fast cooling $\mathbf{B}(\mathrm{A})$. The thermal inputs of cooling rates are processed to provide the outputs of concentrations of $\mathbf{B}(\mathrm{A})$ and $\mathbf{C}(\mathrm{A})$. This is an example of switching products by a small difference in thermal input, which is exerted by the competitive chemical reactions (Figure 8).

The chemical reaction $2 \mathrm{~A}(\mathrm{~A}) \rightarrow \mathbf{C}(\mathrm{A})$ under an isothermal condition of $40^{\circ} \mathrm{C}$ provides sigmoidal kinetics, in which the initial flat domain for 50 min shows the formation of metastable 2A(A) followed by increase in $\Delta \varepsilon$ for the formation of $\mathbf{C}(\mathrm{A})$ (Figure 17c) [66]. The complex nature of this reaction is shown by the formation of $\mathbf{B}(\mathrm{A})$ with negative $\Delta \varepsilon$ below $40^{\circ} \mathrm{C}$.

Heating rate can affect the concentration outputs as well as the cooling rate. When $\mathbf{B}(\mathrm{A})$ is heated from $5{ }^{\circ} \mathrm{C}$ at a rate of $0.1 \mathrm{~K} \mathrm{~min}^{-1}$, a maximum amount of $\mathrm{C}(\mathrm{A})$ is formed at a specific temperature of $45^{\circ} \mathrm{C}$ (Figure $17 \mathrm{~d}$, blue circle), which is then converted to $2 \mathrm{~A}(\mathrm{~A})$ at $60^{\circ} \mathrm{C}$ [67]. By contrast, when $\mathrm{B}(\mathrm{A})$ is heated at a rate of $1 \mathrm{~K} \mathrm{~min}^{-1}, 2 \mathrm{~A}(\mathrm{~A})$ is formed at $45^{\circ} \mathrm{C}$ without $\mathrm{C}(\mathrm{A})$ (Figure 17a). Thus, the slow heating of $\mathbf{B}(\mathrm{A})$ provides $\mathrm{C}(\mathrm{A})$ and fast heating $2 \mathrm{~A}(\mathrm{~A})$ at $40^{\circ} \mathrm{C}$. The thermal hysteresis of $2 \mathrm{~A}(\mathrm{~A}), \mathbf{B}(\mathrm{A})$, and $\mathrm{C}(\mathrm{A})$ exhibits complex increases and decreases in concentrations (Figures 16 and 17),

Temperature range affects thermal hysteresis. When $\mathrm{C}(\mathrm{A})$ is heated from $5^{\circ} \mathrm{C}$ to $60^{\circ} \mathrm{C}$ and cooled to $5^{\circ} \mathrm{C}$ at a rate of $2 \mathrm{~K} \mathrm{~min}^{-1}, \mathbf{B}(\mathrm{A})$ is formed (Figure $17 \mathrm{~d}$, red circle). By contrast, when $\mathrm{C}(\mathrm{A})$ is heated to $55^{\circ} \mathrm{C}$ and cooled at a rate of $1 \mathrm{~K} \mathrm{~min}^{-1}, \mathrm{C}(\mathrm{A})$ is formed without forming $\mathbf{B}(\mathrm{A})$ (Figure 17e, red circle). A difference of $5{ }^{\circ} \mathrm{C}$ at the highest temperature changes the products $\mathbf{B}(\mathrm{A})$ and $\mathbf{C}(\mathrm{A})$ upon cooling. This effect is another example of a switch between products because of a small difference in thermal input. These phenomena 
are due to the involvement of two competitive self-catalytic chemical reactions, which are significantly accelerated by small differences in thermal inputs (Figure 8).

Thermal input/concentration output systems processed by competitive reversible chemical reactions $2 \mathrm{~A}(\mathrm{~A}) \mathrm{B}(\mathrm{A}) \mathrm{C}(\mathrm{A})$ involving two competitive self-catalytic chemical reactions $2 \mathrm{~A}(\mathrm{~A})+\mathrm{C}(\mathrm{A}) \rightarrow 2 \mathrm{C}(\mathrm{A})$ and $2 \mathrm{~A}(\mathrm{~A})+\mathbf{B}(\mathrm{A}) \rightarrow 2 \mathrm{~B}(\mathrm{~A})$ can exhibit diverse bistability phenomena depending on thermal inputs (Figure 8$)$. The thermal inputs described in this section include high or low temperature, cooling or heating states, and slow or fast cooling and heating states. The system can convert the analog thermal signals into digital signals of different concentrations of $\mathbf{B}(\mathrm{A})$ and $\mathbf{C}(\mathrm{A})$. The right-handed and left-handed helix senses of $\mathbf{B}(\mathrm{A})$ and $\mathbf{C}(\mathrm{A})$ with a large difference in the three-dimensional molecular structures may be beneficial for interfacing with other systems. Memory effect and future predicting also appear.

\subsection{Cooling History}

Sections 5.1-5.3 described concentration outputs against thermal inputs as depicted by concentration $(\Delta \varepsilon) /$ temperature profiles. Thermal inputs can provide the outputs of reaction rates, which are changes in concentrations depicted by concentration $(\Delta \varepsilon) /$ time profiles. Cooling history, which involves different courses of temperature changes from a high temperature to a low temperature before initiating the chemical reaction, significantly changes the reaction rates. Therefore, the fast and slow chemical reactions provide bistability by different concentrations at a certain period of time after the initiation because of the two competitive self-catalytic chemical reactions $2 \mathrm{~A}(\mathrm{~A})+\mathrm{C}(\mathrm{A}) \rightarrow 2 \mathrm{C}(\mathrm{A})$ and $2 \mathbf{A}(\mathrm{A})+\mathbf{B}(\mathrm{A}) \rightarrow 2 \mathbf{B}(\mathrm{A})$ (Figure 8 )

The thermal history of cooling rate provides different reaction rates. A mixture of $(P)-7$ and $(M)-8$ in fluorobenzene $(0.5 \mathrm{mM})$ was heated to $70^{\circ} \mathrm{C}$ to form fully dissociated $2 \mathrm{~A}(\mathrm{~A})$, rapidly cooled to $-10{ }^{\circ} \mathrm{C}$, rapidly heated to $25{ }^{\circ} \mathrm{C}$, and allowed to settle at the temperature [66]. Then, chemical reaction at $25^{\circ} \mathrm{C}$ occurred to form $\mathrm{C}(\mathrm{A})$, which completed in $5 \mathrm{~h}$ (Figure 18a). In contrast, when $2 \mathrm{~A}(\mathrm{~A})$ at $70{ }^{\circ} \mathrm{C}$ was cooled to $-10{ }^{\circ} \mathrm{C}$ at a rate of $2 \mathrm{~K} \mathrm{~min}^{-1}$, rapidly heated to $25^{\circ} \mathrm{C}$, and settled, the chemical reaction to form $\mathrm{C}(\mathrm{A})$ completed in $84 \mathrm{~h}$. A large difference in reaction rate was observed in the formation of $\mathrm{C}(\mathrm{A})$, providing bistability in $\mathrm{C}(\mathrm{A})$ concentrations between 80 and $300 \mathrm{~min}$ (Figure 18b, red bold lines). The rapid cooling history to $-10{ }^{\circ} \mathrm{C}$ provides $\Delta \varepsilon$ of approximately $+400 \mathrm{~cm}^{-1} \mathrm{M}^{-1}$, containing approximately $100 \%$ of $\mathrm{C}(\mathrm{A})$ between 80 and $300 \mathrm{~min}$, and the slow cooling history provided $\Delta \varepsilon$ of approximately $-250 \mathrm{~cm}^{-1} \mathrm{M}^{-1}$ containing approximately $20 \%$ of $\mathrm{C}(\mathrm{A})$. The large difference in the concentrations and three-dimensional structures of $2 \mathrm{~A}(\mathrm{~A})$ and $\mathrm{C}(\mathrm{A})$ during the period may be beneficial for interfacing.

(a)

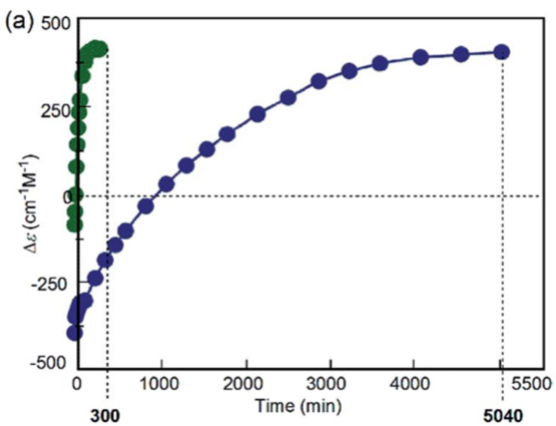

(b)

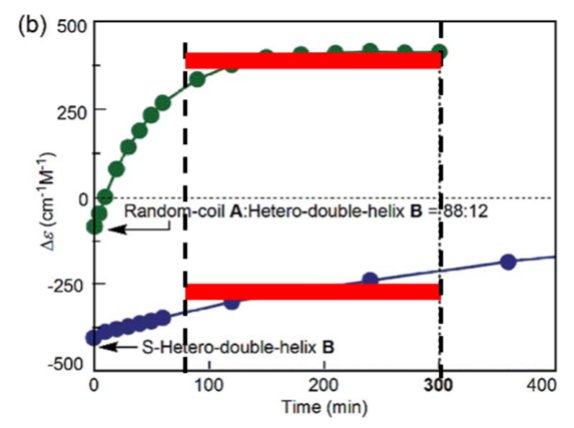

Figure 18. (a) Chemical kinetics of $(P)-7$ and $(M)-8$ in fluorobenzene $(0.5 \mathrm{mM})$ at $25{ }^{\circ} \mathrm{C}$ by the procedures of rapid cooling to $-10^{\circ} \mathrm{C}$ and rapid heating to $25^{\circ} \mathrm{C}$ (green line), and cooling from 70 to $-10^{\circ} \mathrm{C}$ at a rate of $2 \mathrm{~K} \mathrm{~min}^{-1}$ and rapid heating to $25^{\circ} \mathrm{C}$ (blue line). (b) Expansion of (a) at the initial state. Red bold lines indicate bistability. Reproduced from ref. [66]. 
Another cooling history is provided as follows. When fully dissociated $2 \mathrm{~A}(\mathrm{~A})$ at $70{ }^{\circ} \mathrm{C}$ was rapidly cooled to $25^{\circ} \mathrm{C}$, an extremely slow reaction occurred during the formation of C(A), which was completed after $60 \mathrm{~h}$ (Figure 19b). By contrast, when $2 \mathrm{~A}(\mathrm{~A})$ at $70{ }^{\circ} \mathrm{C}$ was rapidly cooled to $-25^{\circ} \mathrm{C}$ and rapidly heated to $25^{\circ} \mathrm{C}$, a fast reaction that formed $\mathrm{C}(\mathrm{A})$ occurred, which was completed in $4 \mathrm{~h}$ (Figure 19a). In both experiments at $25^{\circ} \mathrm{C}$ within the initial $2 \mathrm{~min}$, the same CD, ${ }^{1} \mathrm{H}-\mathrm{NMR}$, and DLS data of $2 \mathrm{~A}(\mathrm{~A})$ were obtained. Then, the rapid cooling history of $2 \mathrm{~A}(\mathrm{~A})$ to $-10{ }^{\circ} \mathrm{C}$ and $-25^{\circ} \mathrm{C}$ before the initiation of the chemical reaction that form $\mathrm{C}(\mathrm{A})$ at $25^{\circ} \mathrm{C}$ significantly increased the reaction rate. The enhanced reaction rate that resulted in the formation of $\mathbf{C}(\mathrm{A})$ from $2 \mathrm{~A}(\mathrm{~A})$ was derived from two competitive self-catalytic chemical reactions, which amplified subtle differences below the detection at $25^{\circ} \mathrm{C}$ generated by the cooling history (Figure 8).

(a)

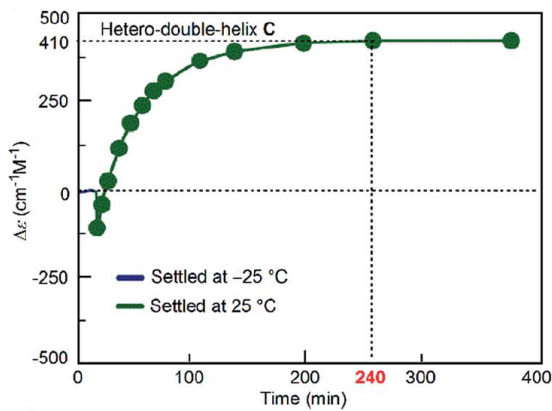

(b)

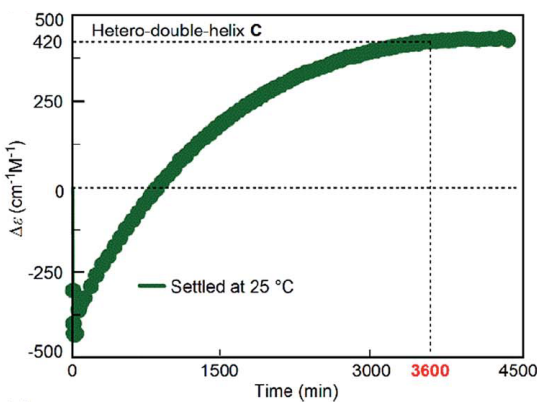

(c)

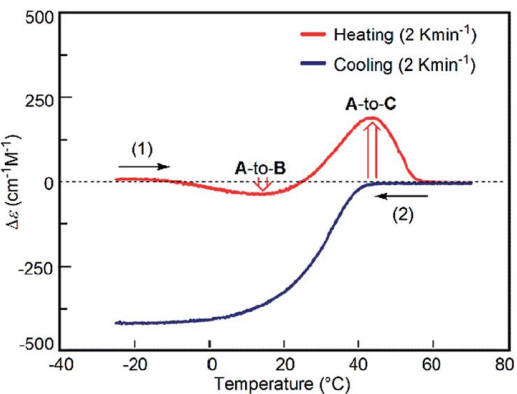

Figure 19. Chemical kinetics of $(P)-7$ and $(M)-8$ at $25^{\circ} \mathrm{C}$ in fluorobenzene $(0.5 \mathrm{mM})$ during (a) rapid cooling to $-25^{\circ} \mathrm{C}$ and rapid heating to $25^{\circ} \mathrm{C}$ and (b) rapid cooling from 70 to $25^{\circ} \mathrm{C}$. (c) Heating and cooling experiment at a rate of $2 \mathrm{~K} \mathrm{~min}^{-1}$ between $-25^{\circ} \mathrm{C}$ and $70^{\circ} \mathrm{C}$. Reproduced from ref. [66].

The significant effect of the cooling history is ascribed to difference in temperature dependency among the competitive self-catalytic chemical reactions $2 \mathrm{~A}(\mathrm{~A})+\mathrm{C}(\mathrm{A}) \rightarrow 2 \mathrm{C}(\mathrm{A})$ and $2 \mathbf{A}(\mathrm{A})+\mathbf{B}(\mathrm{A}) \rightarrow 2 \mathbf{B}(\mathrm{A})$ (Figure $19 \mathrm{c}$ ). The heating of $2 \mathbf{A}(\mathrm{A})$ from $-25^{\circ} \mathrm{C}$ at a rate of $2 \mathrm{~K}$ $\mathrm{min}^{-1}$ predominantly results in the formation of $\mathbf{B}(\mathrm{A})$ below $25^{\circ} \mathrm{C}$ and $\mathrm{C}(\mathrm{A})$ above $25^{\circ} \mathrm{C}$; cooling of $2 \mathrm{~A}(\mathrm{~A})$ from $70{ }^{\circ} \mathrm{C}$ results in the formation of $\mathbf{B}(\mathrm{A})$. The switching phenomenon in the chemical reactions that form $\mathbf{B}(\mathrm{A})$ and $\mathbf{C}(\mathrm{A})$ is different from ordinary competitive chemical reactions, which generally do not switch products as temperature changes, as noted in Section 2.2.

Memory of cooling history to $-10^{\circ} \mathrm{C} /-25^{\circ} \mathrm{C}$ significantly accelerates the chemical reaction to form $\mathrm{C}(\mathrm{A})$, when compared with the same chemical reaction involving different cooling history. Therefore, different future occurs with regard to the reaction rate for the formation $\mathrm{C}(\mathrm{A})$ from $2 \mathrm{~A}(\mathrm{~A})$ by a different memory of history.

\section{Concentration Threshold}

Section 5 described thermal input/concentration output systems processed by chemical reactions and their interfacing with other systems with regard to large differences in concentration and three-dimensional structures, ultimately relating resources to functions in the real world (Figure 1). Concentration threshold by chemical reactions can be a methodology for enhancing efficiency for interfacing, which amplifies small differences in concentration. A chemical reaction rapidly occurs above a threshold concentration and not below. It is in contrast to small changes in product concentration by ordinary chemical equilibria and chemical reactions by small changes in concentration (Section 2.2).

The concentration threshold of $(P)-\mathbf{1}$ appears in response to a small change in total concentration. $(P)-\mathbf{1}$ in 1,3-difluorobenzene at a total concentration of $0.7 \mathrm{mM}$ after heating to $70^{\circ} \mathrm{C}$, cooling to $47^{\circ} \mathrm{C}$, and repeated change in temperature between $47^{\circ} \mathrm{C}$ and $49{ }^{\circ} \mathrm{C}$ at a rate of $0.25 \mathrm{~K} \mathrm{~min}^{-1}$ (Figure 20a) [67]. Continuous increases in $\Delta \varepsilon$ upon cooling and heating occur during the formation of thermodynamically stable $\mathbf{B}(S)$. The phenomenon 
involves self-catalytic chemical reaction $2 \mathbf{A}(\mathrm{S})+\mathbf{B}(\mathrm{S}) \rightarrow 2 \mathbf{B}(\mathrm{S})$, which, once started, does not retard or stop by cooling and heating. At a total concentration of $0.6 \mathrm{mM}$ or below, essentially no reaction occurs upon cooling and heating between $47^{\circ} \mathrm{C}$ and $49^{\circ} \mathrm{C}$. A small difference in the initial concentration of $2 \mathbf{A}(\mathrm{A})$ between 0.6 and $0.7 \mathrm{mM}$ resulted in a large difference in the concentration of $\mathbf{B}(\mathrm{S})$, and this significant difference may be beneficial for interfacing with other systems. The thermal input of repeated temperature change enhances the difference in the concentration of $\mathbf{B}(\mathrm{S})$ at $0.7 \mathrm{mM}$. After the second heating, the concentration of $\mathbf{B}(\mathrm{A})$ at $0.7 \mathrm{mM}$ is eight times that at $0.6 \mathrm{mM}$. This result is a property of reversible chemical reaction out of chemical equilibrium (Figure 4c).

(a)

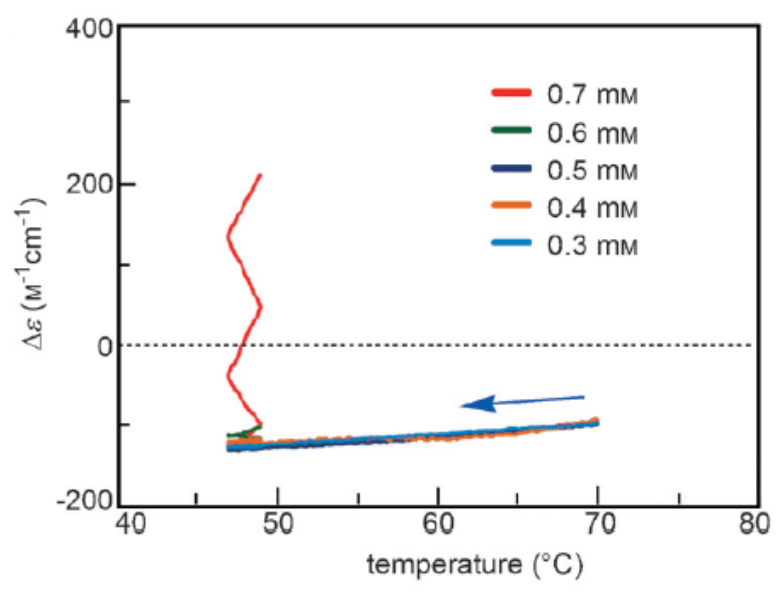

(b)

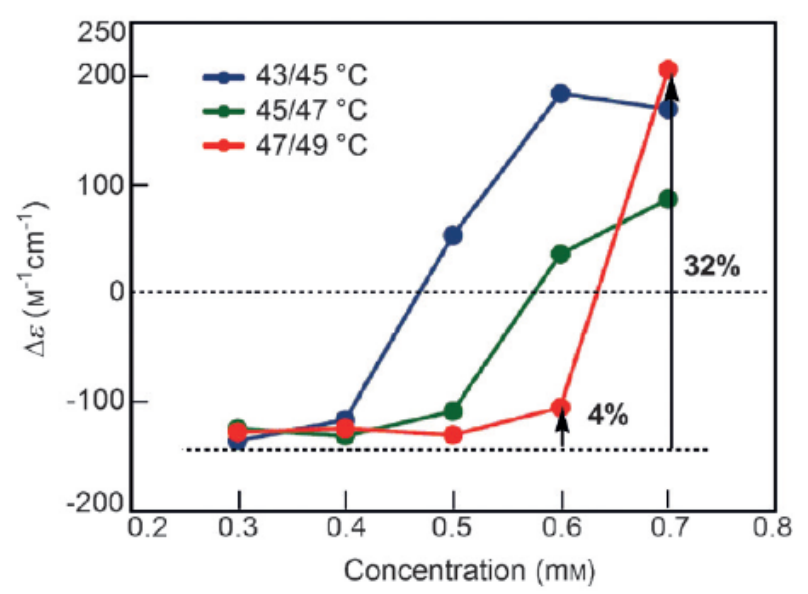

Figure 20. (a) Concentration threshold of $(P)-\mathbf{1}$ in 1,3-difluorobenzene by repeated temperature changes between 47 and $49^{\circ} \mathrm{C}$. (b) Experiments at different concentrations shown by $\Delta \varepsilon$ at the second heating. Reproduced from ref. [67] with permission from Wiley.

The threshold concentration can be fine-tuned by temperature ranges. Changing between $45^{\circ} \mathrm{C}$ and $47^{\circ} \mathrm{C}$ provides a threshold concentration between 0.5 and $0.6 \mathrm{mM}$; changing between $43{ }^{\circ} \mathrm{C}$ and $45^{\circ} \mathrm{C}$ provides concentrations between 0.4 and $0.5 \mathrm{mM}$ (Figure 20b). This is fine-tunability of the threshold concentration, which can be employed for parallel processing (Figure 9).

\section{Interfacing of Concentration Outputs with Other Input/Output Systems}

The above discussions have described thermal input/concentration output systems processed by chemical reactions. The chemical basis for the properties of the chemical reactions includes reversibility out of equilibrium, bistability involving metastable states with sigmoidal relationship or kinetics, positive feedback by self-catalytic chemical reactions, competitive chemical reactions, and fine-tunability for parallel processing. Stepwise and gradient temperature changes are provided to the systems, which process thermal inputs, such as high or low temperature, cooling or heating states, slow or fast cooling and heating states, and precooling history. Then, outputs with concentrations of substrates and products with large differences are obtained. The input/output systems can convert various sophisticated thermal inputs into concentration outputs.

Therefore, the question is how such outputs can effectively be interfaced with other systems, which eventually convert resources into functions in the real world (Figure 1). Systems processed by chemical reactions are employed in biological systems.

\subsection{Processing by Chemical Reactions and Effective Interfacing}

The properties of chemical reactions, which are beneficial for interfacing with other systems, are considered below. Bistability is a concept involving two rested states at the same 
temperature range, which are interconvertible, and large differences in the concentrations are key for effective interfacing. Large differences in their three-dimensional structures are also preferable. Then, concentration outputs can be employed in other systems without error, which are also processed by chemical reactions. Sigmoidal relationships out of chemical equilibrium enhance the stability of metastable rested states, which provides robustness against thermal perturbations. Positive feedback by self-catalytic chemical reactions amplifies small temperature changes in inputs into large differences in concentration outputs. Competitive chemical reactions providing different products can process various complex thermal phenomena. Processing in a closed system is attractive, which employs simple operations of adding and removing thermal energy without those of materials.

These properties of chemical reactions may be beneficial for interfacing of thermal input/concentration output systems with other systems. However, they are not common properties of ordinary chemical equilibria and bimolecular chemical reactions. The development of such chemical reactions and understanding their properties are worthy of attention.

Implication of efficient interfacing can be better understood by considering the system, which provides the differences in the concentration outputs that are insufficiently large, and amplification of differences is required. Two examples are described below, which employ (1) selective binding with receptors or allosteric catalysts and (2) concentration threshold.

\subsection{Increasing the Efficiency of Interfacing}

Processing in thermal input/concentration output systems is a phenomenon of molecular assembly involving huge numbers of molecules, which is different from those of a single molecule. Therefore, interfacing with other input/output systems needs to involve large differences in concentrations. When the difference is relatively small, employment of selective receptor and allosteric catalysts can be considered in the removal of noises due to minor products.

An input/output system processed by a reversible chemical reaction $2 \mathrm{~A} \quad \mathbf{B}$ and receptor molecules or allosteric catalysts $\mathbf{P}$ in another system, which interacts with $\mathbf{B}$ and exert chemical reaction to form $\mathbf{X}$ and/or $\mathbf{Y}$, should be considered. The reversible chemical reaction $2 \mathrm{~A} \mathbf{B}$ occurs between unstructured random-coil $2 \mathrm{~A}$ and structured homodouble-helix B. When the concentration of $\mathbf{B}$ is considerably larger than $2 \mathbf{A}$ in the output, interfacing through the selective binding of $\mathbf{B}$ with $\mathbf{P}$ over $\mathbf{A}$ can occur. Then, the resulting BP complex exerts chemical reaction that forms $\mathbf{X}$ and $\mathbf{Y}$ (Figure 21a). Such a phenomenon can be termed as an activation mode. A related binding phenomenon has been observed in nanoparticle precipitation, and helicene-grafted nanoparticles selectively remove $\mathbf{B}$ but not 2A from solution through molecular recognition and precipitation [68]. 
(a)

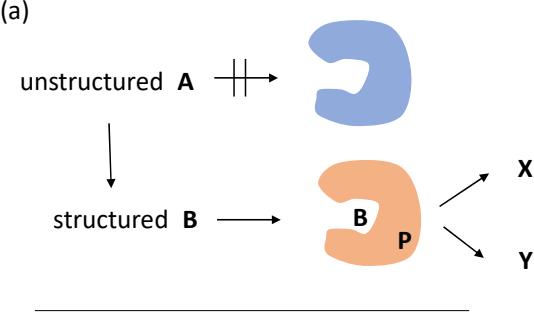

(c)

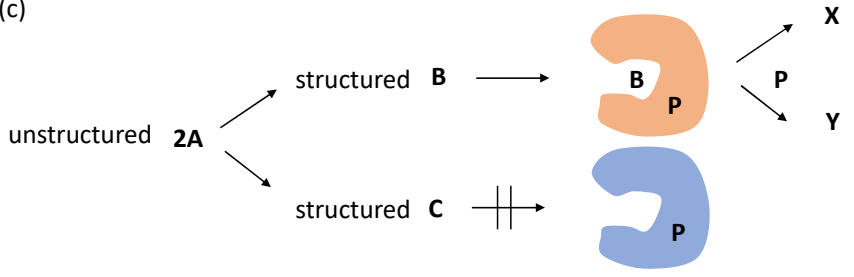

(b) $Y$

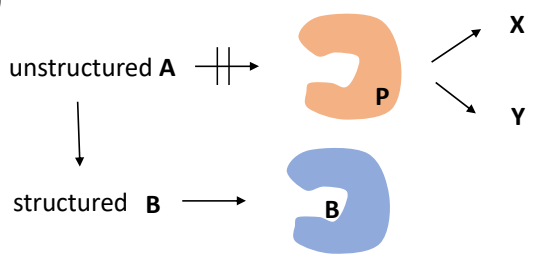<smiles>[LiH]</smiles>

Figure 21. Interfacing of output processed by reversible chemical reaction $2 \mathbf{A} \mathbf{B}$, in which $2 \mathbf{A}$ is unstructured random-coil and $\mathbf{B}$ is structured homo-double-helix. (a) Activation mode and (b) deactivation mode in the binding of $\mathbf{B}$ over $\mathbf{A}$ with a receptor or allosteric catalyst $\mathbf{P}$, which exerts the formation of $\mathbf{X}$ and/or $\mathbf{Y}$. (c) Interfacing of output derived from reversible competitive chemical reactions $\mathbf{B} 2 \mathrm{~A} \mathbf{C}$ by activation mode. Orange figure indicates active $\mathbf{P}$ and blue inactive $\mathbf{P}$.

In contrast, when the concentration of unstructured $\mathbf{A}$ is considerably larger than that of structured $\mathbf{B}$ in the output, the selective binding of $\mathbf{A}$ with $\mathbf{P}$ over $\mathbf{B}$ may not readily occur because the structure of A fluctuates. The deactivation mode can then be employed, which involves the inhibition of the chemical reaction that induces the formation of $\mathbf{X}$ and $\mathbf{Y}$ by the BP complex, which is formed through the binding of $\mathbf{P}$ and $\mathbf{B}$ (Figure 21b). When the concentration of $\mathbf{A}$ is considerably larger than $\mathbf{B}$, the chemical reaction by $\mathbf{P}$ to form $\mathbf{X}$ and $\mathbf{Y}$ occurs. In contrast, decrease in $\mathbf{A}$ and increase in $\mathbf{B}$ form $\mathbf{B P}$ complex, which inhibits the chemical reaction for the formation of $\mathbf{X}$ and $\mathbf{Y}$.

Interfacing by reversible competitive chemical reactions $\mathbf{B} \rightleftharpoons 2 \mathrm{~A} \rightleftharpoons \mathbf{C}$ is also considered, which facilitates the binding of structured $\mathbf{B}$ or $\mathbf{C}$ with $\mathbf{P}$ in other systems (Figure 21c). In such a case, the concentration differences between $\mathbf{B}$ and $\mathbf{C}$ can be enhanced by the selective binding of $\mathbf{B}$ over $\mathbf{C}$. For instance, when binding constant $K$ for $\mathbf{P}$ and $\mathbf{B}$ is $10^{4}$ times larger than that of $\mathbf{C}$, the apparent concentration difference can be increased $10^{4}$ times, and chemical reaction by $\mathbf{B P}$ complex to form $\mathbf{X}$ and $\mathbf{Y}$ is predominant compared with that of the $\mathbf{C P}$ complex (activation mode).

The properties of thermal input/concentration output systems can be analyzed in homogeneous solutions because the properties of dispersed molecules are relatively simple and easy to understand. However, for the purpose of effective interfacing, aggregated receptors and allosteric catalysts, such as $\mathbf{P}_{\mathrm{n}}$ with ordered structures, can be more efficient because of the close contact of $\mathbf{P}$ molecules with one another. This property can promote the formation of BP complexes through self-catalytic reactions. Then, chemical reaction for the formation of $\mathbf{X}$ and $\mathbf{Y}$ can be accelerated. Biological cells employ such aggregated protein clusters on cell surface.

Another methodology for effective interfacing with another system involves the amplification of concentration differences, in which concentration threshold phenomena can be employed (Section 6). For instance, in the input/output system providing B and $\mathbf{C}$, when the chemical reaction of $\mathbf{B P}$ complex for the formation of $\mathbf{X}$ and $\mathbf{Y}$ occurs above a concentration threshold of $\mathbf{B}$ but not $\mathbf{C}$, the apparent concentration of $\mathbf{B}$ can be increased.

Diverse effective chemical devices can be considered for interfacing, which reduce noise due to minor compounds. Such enhancement of concentration differences may be another interesting subject in chemistry. 


\section{Conclusions}

The concept of input/output systems are broadly employed in science, technology, and society. Inputs are signals received by systems, whereas outputs are signals sent from the systems. Between input and output is processing, which is how inputs are related to outputs. The systems are connected by interfacing, which eventually converts resources, such as energy, materials, and environments, into functions in our real world (Figure 1).

Processing by chemical reactions in input/output systems is essential to biological cells, and such chemical reactions involve the rearrangement of chemical bonds through covalent or noncovalent bonds. However, biological systems are extremely complex, and thus experimental studies on synthetic input/output systems can promote our understanding of biological events and development of materials functions. A chemical reaction itself contains diverse information on temperature, concentration, structures of substrates and products, and media because a chemical reaction generally occurs under a limited condition and substrates. In addition, sophisticated inputs can be processed by chemical reactions.

This article focused on synthetic thermal input/concentration output systems processed by chemical reactions using helicene oligomers (Figure 2). The systems can process various sophisticated thermal inputs, which include high or low temperature, cooling or heating states, slow or fast cooling and heating states, and precooling history. The chemical basis for the properties of the chemical reactions involved in the systems include reversibility out of chemical equilibrium, sigmoidal relationship and kinetics, bistability involving metastable states, positive feedback by self-catalytic chemical reactions, competitive chemical reactions, and fine-tunability for parallel processing. Interfacing with other systems is also described. A list of chemical bases for the properties of such chemical reactions is provided, and a novel concept of chemical reaction is introduced.

Author Contributions: Conceptualization and writing-original draft preparation, M.Y.; writingreview and editing, S.Z. Conceptualization and writing-original draft preparation, M.Y.; writingreview and editing, S.Z. and M.B.; visualization, S.Z.; data analyses, M.B. All authors have read and agreed to the published version of the manuscript.

Funding: This research was funded by the National Natural Science Foundation of China, grant number 21573032, the Fundamental Research Funds for the Central Universities, grant number DUT20LK42 and LiaoNing Revitalization Talents Program, grant number XLYC1802030.

Informed Consent Statement: Not applicable.

Conflicts of Interest: The authors declare no conflict of interest.

\section{References}

1. Boell, S.; Cecez-Kecmanov, D. Conceptualizing Information Systems: From Input-Processing-Output Devices to Sociomaterial Apparatuses. ECIS 2012 Proc. 2012. Paper 20. Available online: http:/ / aisel.aisnet.org/ecis2012/20 (accessed on 1 November 2021).

2. Input/Output. Available online: https://en.wikipedia.org/wiki/Input/output (accessed on 1 November 2021).

3. Input Output Model; Six Sigma Daily. Available online: https://www.sixsigmadaily.com/input-output-model/ (accessed on 1 November 2021).

4. Input Interfacing Circuits; Electronic Tutorials. Available online: https://www.electronics-tutorials.ws/io/input-interfacingcircuits.html (accessed on 1 November 2021).

5. Input Output Interface. Available online: https://www.sciencedirect.com/topics/engineering/input-output-interface (accessed on 1 November 2021).

6. Introduction to Input-Output Interface; GeeksforGeeks. Available online: https://www.geeksforgeeks.org/introduction-toinput-output-interface/ (accessed on 1 November 2021).

7. Electronic Systems. Available online: https://www.electronics-tutorials.ws/systems/electronic-system.html (accessed on 1 November 2021).

8. Digital I/O and Analog I/O; Electrical Classroom. Available online: https:/ /www.electricalclassroom.com/digital-i-o-andanalog-i-o/ (accessed on 1 November 2021).

9. Digital Signal Processing. Available online: https://en.wikipedia.org/wiki/Digital_signal_processing (accessed on 1 November 2021).

10. Analog Signal Processing. Available online: https:/ / en.wikipedia.org/wiki/Analog_signal_processing (accessed on 1 November 2021). 
11. Electronic Circuit. Available online: https://en.wikipedia.org/wiki/Electronic_circuit (accessed on 1 November 2021).

12. Zwass, V. Information System; Encyclopedia Britannica. Available online: https://www.britannica.com/topic/informationsystem (accessed on 1 November 2021).

13. Data Processing; Encyclopedia Britannica. Available online: https://www.britannica.com/technology/data-processing (accessed on 1 November 2021).

14. Lodish, H.; Berk, A.; Kaiser, C.A.; Krieger, M.; Bretscher, A.; Ploegh, H.; Amon, A.; Martin, K.C. Molecular Cell Biology, 8th ed.; W.H. Freeman \& Company: New York, NY, USA, 2016.

15. Signal Transduction. Available online: https://en.wikipedia.org/wiki/Signal_transduction (accessed on 1 November 2021).

16. Otero-Muras, I.; Banga, J.R.; Alonso, A.A. Characterizing multistationarity regimes in biochemical reaction networks. PLoS ONE 2012, 7, e39194. [CrossRef] [PubMed]

17. Ferrell, J.E., Jr.; Xiong, W. Bistability in cell signaling: How to make continuous processes discontinuous, and reversible processes irreversible. Chaos 2001, 11, 227. [CrossRef] [PubMed]

18. Daniel, R.; Rubens, J.R.; Sarpeshkar, R.; Lu, T.K. Synthetic analog computation in living cells. Nature 2013, 497, 619-624. [CrossRef]

19. Bradley, R.W.; Wang, B. Designer cell signal processing circuits for biotechnology. New Biotechnol. 2015, 32, 635-643. [CrossRef] [PubMed]

20. Sarpeshkar, R. Analog synthetic biology. Phil. Trans. Royal. Soc. A 2014, 372, 20130110. [CrossRef] [PubMed]

21. Tyson, J.J.; Chen, K.C.; Novak, B. Sniffers, buzzers, toggles and blinkers: Dynamics of regulatory and signaling pathways in the cell. Curr. Opin. Cell Biol. 2003, 15, 221-231. [CrossRef]

22. Signal Processing. Available online: https://en.wikipedia.org/wiki/Signal_processing (accessed on 1 November 2021).

23. Bear, M.F.; Connors, B.W.; Paradiso, M.A. Neuroscience: Exploring the Brain, 4th ed.; Jones \& Bartlett Learning, LLC: Burlington, VT, USA, 2016

24. Systems Biology. Available online: https://en.wikipedia.org/wiki/Systems_biology (accessed on 1 November 2021).

25. Systems Biology as Defined by NIH; National Institutes of Health Webpage. Available online: https://irp.nih.gov/catalyst/v19i6 / systems-biology-as-defined-by-nih (accessed on 1 November 2021).

26. Cosentino, C.; Bates, D. Feedback Control in Systems Biology; CRC Press: Boca Raton, FL, USA, 2011.

27. Angeli, D. A Tutorial on Chemical Reaction Network Dynamics. Eur. J. Control. 2009, 3-4, 398-406. [CrossRef]

28. Afroz, A.; Beisel, C.L. Understanding and exploiting feedback in synthetic biology. Chem. Eng. Sci. 2013, 103, 79-90. [CrossRef]

29. Yamaguchi, M. Thermal hysteresis involving reversible self-catalytic reactions. Acc. Chem. Res. 2021, 54, 2603-2613. [CrossRef]

30. Shigeno, M.; Kushida, Y.; Yamaguchi, M. Molecular switching involving metastable states: Molecular thermal hysteresis and sensing of environmental changes by chiral helicene oligomeric foldamers. Chem. Commun. 2016, 52, 4955-4970. [CrossRef] [PubMed]

31. Shigeno, M.; Kushida, Y.; Yamaguchi, M. Energy aspects of thermal molecular switching: Molecular thermal hysteresis of helicene oligomers. Chem. Phys. Chem. 2015, 16, 2076-2083. [CrossRef] [PubMed]

32. Levine, R.D.; Bernstein, R.B. Molecular Reaction Dynamics; Cambridge University Press: Cambridge, UK, 2009.

33. Wright, M.R. Fundamental Chemical Kinetics; Horwood Publishing Limited: Woodgate, UK, 1999.

34. Steinfeld, J.I.; Francisco, J.S.; Hase, W.L. Chemical Kinetics and Dynamics; Prentice-Hall Inc.: Upper Saddle River, NJ, USA, 1989.

35. Atkins, P.; de Paula, J. Physical Chemistry, 10th ed.; Oxford University Press: Oxford, UK, 2014.

36. Vyazovkin, S.; Wight, C.A. Isothermal and non-isothermal kinetics of thermally stimulated reactions of solids. Int. Rev. Phys. Chem. 1998, 17, 407-433. [CrossRef]

37. Várhegyi, G. Empirical models with constant and variable activation energy for biomass pyrolysis. Energy Fuels 2019, 33, 2348-2358. [CrossRef]

38. Smith, I.W.M. The temperature-dependence of elementary reaction rates: Beyond Arrhenius. Chem. Soc. Rev. 2008, 37, 812-826. [CrossRef] [PubMed]

39. Carvalho-Silva, V.H.; Coutinho, N.D.; Aquilanti, V. Temperature dependence of rate processes beyond Arrhenius and Eyring: Activation and transitivity. Front. Chem. 2019, 7, 380. [CrossRef]

40. Vyazovkin, S. A time to search: Finding the meaning of variable activation energy. Phys. Chem. Chem. Phys. 2016, 18, 18643-18656. [CrossRef]

41. Bistability. Available online: https:/ / en.wikipedia.org/wiki/Bistability (accessed on 1 November 2021).

42. Wilhelm, T. A definition of bistability in systems biology. BMC Syst. Biol. 2009, 3, 90.

43. Heaviside Step Function. Available online: https://en.wikipedia.org/wiki/Heaviside_step_function (accessed on 1 November 2021).

44. Sigmoid Function. Available online: https://en.wikipedia.org/wiki/Sigmoid_function (accessed on 1 November 2021).

45. Ueno, H.; Tsuruyama, T.; Nowakowski, B.; Gorecki, J.; Yoshikawa, K. Discrimination of time-dependent inflow properties with a cooperative dynamical system. Chaos 2015, 25, 103115. [CrossRef]

46. Frank, S.A. Input-output relations in biological systems: Measurement, information and the Hill equation. Biol. Direct 2013, 8, 31. [CrossRef]

47. Qian, H. Cooperativity in Cellular Biochemical Processes. Ann. Rev. Biophys. 2012, 41, 179-204. [CrossRef] [PubMed]

48. Positive Feedback; Biology Dictionary. Available online: https://biologydictionary.net/positive-feedback/ (accessed on 1 November 2021). 
49. Feedback Control in Biological Interactions; MCB111: Mathematics in Biology (Fall 2021). Available online: http://mcb111.org/ w11/w11-lecture.html (accessed on 1 November 2021).

50. Zeron, E.S. Positive and negative feedback in engineering and biology. Math. Model. Nat. Phenom. 2008, 3, 67-84. [CrossRef]

51. Alberts, B.; Johnson, A.; Lewis, J.; Morgan, D.; Raff, M.; Roberts, K.; Walter, P. Molecular Biology of the Cell; Garland Science: New York, NY, USA, 2014.

52. Sawato, T.; Saito, N.; Yamaguchi, M. Chemical systems involving two competitive self-catalytic reactions. ACS Omega 2019, 4, 5879-5899. [CrossRef] [PubMed]

53. Sawato, T.; Yamaguchi, M. Synthetic chemical systems involving self-catalytic reactions of helicene oligomer foldamers. Chem. Plus Chem. 2020, 85, 2017-2038. [CrossRef]

54. Rovelli, C. Memory and entropy. arXiv 2020, arXiv:2003.06687. Available online: https://arxiv.org/abs/2003.06687 (accessed on 1 November 2021).

55. Nakasone, Y.; Ono, T.; Ishii, A.; Masuda, S.; Terazima, M. Temperature-sensitive reaction of a photosensor protein YcgF: Possibility of a role of temperature sensor. Biochemistry 2010, 49, 2288-2296. [CrossRef]

56. Enoki, S.; Watanabe, R.; Iino, R.; Noji, H. Single-molecule study on the temperature-sensitive reaction of $F_{1}$-ATPase with a hybrid $\mathrm{F}_{1}$ carrying a single b(E190D). J. Biol. Chem. 2009, 284, 23169-23176. [CrossRef]

57. García-Ávila, M.; Islas, L.D. What is new about mild temperature sensing? A review of recent findings. Temperature 2019, 6, 132-141. [CrossRef]

58. Dhaka, A.; Viswanath, V.; Patapoutian, A. TRP ion channels and temperature sensation. Ann. Rev. Neurosci. 2006, $29,135-161$. [CrossRef]

59. Shigeno, M.; Kushida, Y.; Kobayashi, Y.; Yamaguchi, M. Molecular function of counting the numbers 1 and 2 exhibited by a sulfoneamidohelicene tetramer. Chem. Eur. J. 2014, 20, 12759-12762. [CrossRef]

60. Shigeno, M.; Kushida, Y.; Yamaguchi, M. Molecular thermal hysteresis in helix dimer formation of sulfonamidohelicene oligomer in solution. Chem. Eur. J. 2013, 19, 10226-10234. [CrossRef] [PubMed]

61. Miyagawa, M.; Yagi, A.; Shigeno, M.; Yamaguchi, M. Equilibrium crossing exhibited by an ethynylhelicene (M)-nonamer during random-coil- to-double-helix thermal transition in solution. Chem. Commun. 2014, 50, 14447-14450. [CrossRef] [PubMed]

62. Sawato, T.; Arisawa, M.; Yamaguchi, M. Reversible formation of self-assembly gels containing giant vesicles in trifluoromethylbenzene using oxymethylenehelicene oligomers with terminal $C_{16}$ alkyl groups. Bull. Chem. Soc. Jpn. 2020, 93, 1497-1503. [CrossRef]

63. Auer, S.; Kashchiev, D. Insight into the correlation between lag time and aggregation rate in the kinetics of protein aggregation. Proteins 2010, 78, 2412-2416. [CrossRef]

64. Sawato, T.; Masahiko Yamaguchi, M. Sequential self-catalytic reactions in the formation of hetero-double-helix and their selfassembled gels by pseudoenantiomer mixtures of ethynylhelicene oligomers. Chirality 2020, 32, 824-832. [CrossRef] [PubMed]

65. Shigeno, M.; Kushida, Y.; Yamaguchi, M. Heating/cooling stimulus induces three-state molecular switching of pseudoenantiomeric aminomethylenehelicene oligomers: Reversible nonequilibrium thermodynamic processes. J. Am. Chem. Soc. 2014, 136, 7972-7980. [CrossRef]

66. Kushida, Y.; Saito, N.; Shigeno, M.; Yamaguchi, M. Multiple competing pathways for chemical reaction: Drastic reaction shortcut for the self-catalytic double-helix formation of helicene oligomers. Chem. Sci. 2017, 8, 1414-1421. [CrossRef]

67. Kushida, Y.; Shigeno, M.; Yamaguchi, M. Concentration threshold and amplification exhibited by a helicene oligomer during helix-dimer formation: A proposal on how a cell senses concentration changes of a chemical. Chem. Eur. J. 2015, 21, 13788-13792 [CrossRef]

68. Miyagawa, M.; Yamaguchi, M. Material clocking by silica nanoparticle precipitation in solution phase that is tunable by organic molecules. ChemPlusChem 2015, 80, 1502-1507. [CrossRef] 